\title{
Atmospheric composition and thermodynamic retrievals from the ARIES airborne FTS system - Part 1: Technical aspects and simulated capability
}

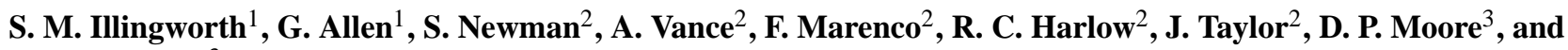 \\ J. J. Remedios ${ }^{3}$ \\ ${ }^{1}$ Centre for Atmospheric Science, University of Manchester, Manchester, M13 9PL, UK \\ ${ }^{2}$ Meteorological Office, Fitzroy Road, Exeter, EX1 3PB, UK \\ ${ }^{3}$ Earth Observation Science, Department of Physics and Astronomy, University of Leicester, University Road, \\ Leicester LE1 7RH, UK
}

Correspondence to: S. Illingworth (samuel.illingworth@manchester.ac.uk)

Received: 25 October 2013 - Published in Atmos. Meas. Tech. Discuss.: 16 December 2013

Revised: 23 March 2014 - Accepted: 25 March 2014 - Published: 30 April 2014

\begin{abstract}
In this study we present an assessment of the retrieval capability of the Airborne Research Interferometer Evaluation System (ARIES): an airborne remote-sensing Fourier transform spectrometer (FTS) operated on the UK Facility for Airborne Atmospheric Measurement (FAAM) aircraft. Simulated maximum a posteriori retrievals of partial column trace gas concentrations, and thermodynamic vertical profiles throughout the troposphere and planetary boundary layer have been performed here for simulated infrared spectra representative of the ARIES system operating in the nadir-viewing geometry. We also describe the operational and technical aspects of the pre-processing necessary for routine retrieval from the FAAM platform and the selection and construction of a priori information. As exemplars of the capability of the ARIES retrieval system, simulated retrievals of temperature, water vapour $\left(\mathrm{H}_{2} \mathrm{O}\right)$, carbon monoxide $(\mathrm{CO})$, ozone $\left(\mathrm{O}_{3}\right)$, and methane $\left(\mathrm{CH}_{4}\right)$, and their corresponding sources of error and potential vertical sensitivity, are discussed for ARIES scenes across typical global environments.

The maximum Degrees of Freedom for Signal (DOFS) for the retrievals, assuming a flight altitude of $7 \mathrm{~km}$, were 3.99 , $2.97,0.85,0.96$, and 1.45 for temperature, $\mathrm{H}_{2} \mathrm{O}, \mathrm{CO}, \mathrm{O}_{3}$, and $\mathrm{CH}_{4}$, respectively, for the a priori constraints specified. Retrievals of temperature display significant vertical sensitivity (DOFS in the range 2.6 to 4.0 across the altitude range) as well as excellent simulated accuracy, with the vertical sensitivity for $\mathrm{H}_{2} \mathrm{O}$ also extending to lower altitudes (DOFS rang-
\end{abstract}

ing from 1.6 to 3.0$)$. It was found that the maximum sensitivity for $\mathrm{CO}, \mathrm{O}_{3}$, and $\mathrm{CH}_{4}$ was approximately $1-2 \mathrm{~km}$ below the simulated altitudes in all scenarios.

Comparisons of retrieved and simulated-truth partial atmospheric columns are used to assess the capability of the ARIES measurement system. Maximum mean biases (and bias standard deviations) in partial columns (i.e. below aircraft total columns) were found to be $+0.06( \pm 0.02$ at $1 \sigma) \%$, $+3.95( \pm 3.11) \%,+3.74( \pm 2.97) \%,-8.26( \pm 4.64) \%$, and $+3.01( \pm 2.61) \%$ for temperature, $\mathrm{H}_{2} \mathrm{O}, \mathrm{CO}, \mathrm{O}_{3}$, and $\mathrm{CH}_{4}$, respectively, illustrating that the retrieval system performs well compared to an optimal scheme. The maximum total a posteriori retrieval errors across the partial columns were also calculated, and were found to be $0.20,22.57,18.22$, 17.61, and $16.42 \%$ for temperature, $\mathrm{H}_{2} \mathrm{O}, \mathrm{CO}, \mathrm{O}_{3}$, and $\mathrm{CH}_{4}$, respectively.

\section{Introduction}

Many atmospheric trace gases of importance to air quality, environmental monitoring and climate change are now being retrieved with increasing success from infrared remotesensing instruments, as improvements in instrument design and reference spectroscopic data sets continue to become available. Much of the focus of past infrared remotesensing spectrometer instruments has been on the retrieval of 
greenhouse gases (GHGs) and chlorofluorocarbons (CFCs) in the context of their importance for the Earth's radiative energy budget and the stability of the ozone layer. Gases such as water vapour $\left(\mathrm{H}_{2} \mathrm{O}\right)$, carbon dioxide $\left(\mathrm{CO}_{2}\right)$, nitrous oxide $\left(\mathrm{N}_{2} \mathrm{O}\right)$, methane $\left(\mathrm{CH}_{4}\right)$, CFCs, carbon monoxide $(\mathrm{CO})$, and ozone $\left(\mathrm{O}_{3}\right)$, significantly absorb infrared radiation making infrared spectroscopy well suited to the observation and retrieval of these compounds in the atmosphere. Furthermore, profile information for a host of additional trace gases with typically weaker infrared signatures have recently been demonstrated to be retrievable from measured spectra. Initially, these originated from limb-sounding observations of the upper troposphere and lower stratosphere, including important reservoirs of chlorine and nitrogen such as $\mathrm{ClONO}_{2}$ (Höpfner et al., 2007), and organic compounds such as peroxyacetyl nitrate (PAN), formic acid and acetone (Moore and Remedios, 2010; Remedios et al., 2007a), derived from spectra recorded by the Michelson Interferometer for Passive Atmospheric Sounding (MIPAS, Fischer et al., 2008) which flew on the European Space Agency's Envisat platform between 2002 and 2012. Concentration data for many more compounds may yet be achieved with improvements in future instrument design and with more accurate reference spectroscopy for trace gases.

Since the launch of MIPAS, a series of nadir-viewing Fourier transform infraRed (FTIR) satellite spectrometers measuring atmospheric composition now exists. These include greenhouse and trace gas retrievals by the Tropospheric Emission Spectrometer (TES) instrument aboard the EOSAura satellite (see e.g. Kulawik et al., 2006; Verstraeten et al., 2013), the Atmospheric Infrared Sounder (AIRS) instrument on board the EOS-Aqua satellite (see e.g. McMillan et al., 2005; Masiello and Serio, 2013), and the Infrared Atmospheric Sounding Interferometer (IASI) instrument on board the Metop-A and Metop-B satellites (see e.g. Turquety et al., 2004; Razavi et al., 2009; Grieco et al., 2013). Recently the Greenhouse Gases Observing Satellite (GOSAT) has also been used to obtain column averaged dry air mole fractions of $\mathrm{CO}_{2}$ and $\mathrm{CH}_{4}$ (see e.g. Yokota et al., 2009; Ross et al., 2013). Such measurement capability has dramatically increased our ability to assess the impact of human activities on the changing composition of our atmosphere and resulting climate change (see e.g. Eremenko et al., 2008; Crevoisier et al., 2009; Worden et al., 2013).

However, the benefit of large-scale coverage offered by polar orbiting remote sensors is limited by their relatively poor spatial resolution (e.g. $12 \mathrm{~km}$ for IASI) compared to in situ methods, and also by their inability to provide continuous sampling, as discussed by Engel-Cox et al. (2004). Trace gas concentrations have also been retrieved using FTIR instruments at local scales (less than $1 \mathrm{~km}$ ) using ground-based (e.g. Rinsland et al., 2002), balloon-borne (e.g. Albrecht et al., 2002), and airborne spectrometers. In particular, the airborne MIPAS-STR (Woiwode et al., 2012) flown on board the M55 Geophysica aircraft, has performed retrievals for many of the gases discussed above at such scales. Recently, the powerful surface mapping ability permitted by a combination of infrared spectrometer and high-resolution imager described by Gerilowski et al. (2011) has been demonstrated for the Methane Airborne MAPper (MAMAP) instrument. Thorpe et al. (2014) also demonstrated the potential for airborne retrieval techniques, utilising the Airborne Visible/Infrared Imaging Spectrometer (AVIRIS).

The simultaneous remote measurement of multiple trace gas concentrations offers many potential benefits over direct in situ measurements, especially when made from moving platforms such as the UK's Facility for Airborne Atmospheric Measurement (FAAM) aircraft discussed in this work, with the retrieval of vertical profiles and partial columns (i.e. total columns below the aircraft) permitting measurement without having to physically traverse air masses, saving significant time and fuel. In addition, scanning instruments allow rapid mapping of wide areas, enabling applications such as those designed to follow discrete plumes in the Lagrangian frame, which would be extremely difficult to achieve with in situ measurements alone. Furthermore, airborne remote-sensing instruments offer a significant advantage over their satellite counterparts as they can improve vertical sensitivity into the lower layers of the atmosphere, manoeuvring within the troposphere to optimise sensitivity to specific layers of interest. This ability is explored in this paper. Despite this advantage, airborne remote sensing offers its own unique challenges, with any retrieved data needing to be carefully compared to observations in order to understand inherent uncertainties, biases and limitations.

In this study, we demonstrate the use of a retrieval algorithm based on the maximum a posteriori method (see Sect. 4), for the Airborne Research Interferometer Evaluation System (ARIES) open-path-FTIR instrument flown on the UK FAAM BAe-146 aircraft. We characterise the information content and retrieval errors for typical ARIES measurements, and discuss the operational characteristics of the integrated ARIES measurement system operating in the nadirviewing geometry. We will focus here on $\mathrm{CO}, \mathrm{O}_{3}, \mathrm{CH}_{4}, \mathrm{H}_{2} \mathrm{O}$, and temperature, though we anticipate that further retrievals of additional gases will be possible in the future. As accurate retrievals (or knowledge) of atmospheric and surface temperature $\left(T_{\mathrm{s}}\right)$ and emissivity $\left(\varepsilon_{\mathrm{s}}\right)$ are a prerequisite of any successful gas retrieval, we shall also discuss those parameters. The validation of ARIES retrievals and their application to international airborne field campaigns will be discussed in future work.

In addition to the applications discussed above, this new measurement capability may serve as a useful ground-truth data set for current and future satellite instruments, as well as a resource from which to test regional air quality, and global chemistry and transport models. In Sect. 2 we shall further introduce the FAAM aircraft and ARIES. In Sect. 3 we discuss the tailored data pre-processing scheme that can be applied operationally to real observations from ARIES, and in 
Table 1. Summary of ARIES specifications.

\begin{tabular}{ll}
\hline Quantity & Specification \\
\hline Range & $550-3000 \mathrm{~cm}^{-1}$ \\
Resolution & $1 \mathrm{~cm}^{-1}$ max OPD \\
Detectors & MCT/InSb sandwich \& Sterling cycle cooler \\
Views & Zenith, nadir $-5^{\circ}$ to nadir $+55^{\circ}(8$ angles $)$ \\
Scan Rate & 4 double-sided interferograms $/ \mathrm{sec}$. at $1 \mathrm{~cm}^{-1}$ \\
Resolution & Up to 64/sec. at $16 \mathrm{~cm}^{-1}$ \\
Beam splitter & Potassium bromide \\
Independent & 44 mrad (full angle) \\
field of view & \\
Calibration & 2 external, heated, stabilised, BB targets \\
Noise & NEDT 0.2 K for 1 min averaged spectra \\
\hline
\end{tabular}

Sect. 4 we describe the retrieval methodology including the construction of the a priori information. Section 5 presents an analysis of the performance of the retrieval scheme in a number of scenarios using simulated spectra mimicking typical situations encountered by ARIES, while the application to real observations is presented in a parallel study.

\section{The ARIES instrument}

The ARIES is owned and operated by the UK Met Office and described further by Wilson et al. (1999); key instrument specifications are listed in Table 1. ARIES was originally designed as an airborne simulator for the IASI satellite instrument (hence the use of the phrase "evaluation system") and, as such, has been used for calibration-validation activities for IASI during tailored aircraft campaigns conducted by the UK Met Office (e.g. Newman et al., 2012). ARIES is based on an ABB Bomem MB100 interferometer, modified for airborne use, with pointing optics designed by the UK Met Office. It has two temperature-stabilised reference black bodies (typically set to nominal values of 303 and $343 \mathrm{~K}$ ) and is able to operate with a zenith, nadir, or across-track viewing geometry. ARIES has a maximum practical spectral resolution of $1 \mathrm{~cm}^{-1}$ in the range 550 to $3000 \mathrm{~cm}^{-1}$ (corresponding to 3.3 to $18 \mu \mathrm{m}$ ) in the mid-infrared. In comparison the IASI instrument covers the spectral range of $645-2760 \mathrm{~cm}^{-1}$ with an apodised spectral resolution of $0.5 \mathrm{~cm}^{-1}$.

The scan rate of the ARIES instrument allows up to two complete interferometer sweeps per second and the instrument's $44 \mathrm{mrad}$ field of view (full angle) corresponds to a ground independent field of view (GIFOV) of approximately $0.07 \mathrm{~km}^{2}$ in the nadir when flying at $7 \mathrm{~km}$. This reduces to a GIFOV of $\sim 0.01 \mathrm{~km}^{2}$ at $2 \mathrm{~km}$ altitude. In this study, we shall discuss ARIES spectra recorded solely in the nadir.

ARIES flew for the first time in March 1996 on the UK Met Office C-130 aircraft and was installed on the FAAM BAe-146 aircraft in April 2004. Since then ARIES has flown in excess of $1100 \mathrm{~h}$ on the BAe-146, during both operational flying conducted by the Met Office around the British Isles, and on many other specialised field campaigns around the world. Data from ARIES have been used operationally to remotely retrieve surface parameters such as $T_{\mathrm{s}}$ and $\varepsilon_{\mathrm{S}}$ (e.g. Newman et al., 2005; Thelen et al., 2009); and to evaluate the infrared signatures of cirrus clouds (Baran and Francis, 2004), stratus clouds (Rizzi et al., 2001), and Saharan dust aerosol (Highwood et al., 2003). The high spectral resolution and excellent radiometric calibration and noise characteristics of the instrument have also allowed ARIES to be used to validate and characterise improvements in reference spectroscopic data sets such as the HIgh-resolution TRANsmission molecular absorption (HITRAN) database (e.g. Newman and Taylor, 2002; Tjemkes et al., 2003); and to make direct measurements of the $\mathrm{H}_{2} \mathrm{O}$ continuum (Taylor et al., 2003).

In this study, we discuss the retrieval of trace gas concentration and thermodynamic information from ARIES.

The retrievals from the ARIES spectra that are discussed in this study follow on from the work that has been done by both the Scanning High-resolution Interferometer Sounder (S-HIS) and NPOESS/NASA Airborne Sounder Testbed Interferometer (NAST-I) instruments on board the NASA ER-2 aircraft (Tobin et al., 2006; Larar et al., 2011). A potential advantage that the ARIES instrument has over the S-HIS and the NAST-I is these instruments, when flown on board the high altitude ER-2 aircraft, usually operate at an altitude of $20 \mathrm{~km}$ on board a NASA ER-2 aircraft, whereas the ARIES instrument typically operates between 1 and $8 \mathrm{~km}$, resulting in a much smaller GIFOV and potentially improved sensitivity to the lower atmosphere (see Sect. 5).

\section{Operational pre-processing}

In this section, we discuss the technical aspects and design of an operational pre-processor for routine future applications (e.g. for data selection and viewing geometry), as well as the necessary constraints imposed by a moving platform over a potentially variable surface scene. Although such preprocessing is not applicable in the context of the simulations carried out for this study (see Sect. 5), they are an integral component of the operational retrieval system and therefore they are discussed here. In this work the pre-processing and the retrieval using the maximum a posteriori method is referred to collectively as the Manchester Airborne Retrieval Scheme (MARS).

\subsection{Co-addition of spectra}

In order to maximise the computational efficiency of the retrievals, and to reduce random spectral noise resulting from instrument and detector sources, ARIES spectra are co-added over a time interval of $5 \mathrm{~s}(0.2 \mathrm{~Hz})$, corresponding to a ground footprint of approximately $0.25 \mathrm{~km}^{2}$ at a flying altitude of $7 \mathrm{~km}$. This choice of integration time is 
flexible but a value of $5 \mathrm{~s}$ is recommended as a compromise between potential changes in scene homogeneity and viewing geometry, which may affect the validity of assumptions about the ray path and surface source necessary for the radiative transfer model (see following section); and a reduction in the mean noise equivalent spectral radiance (NESR), which improves retrieval accuracy. In addition to this NESR the blackbody calibration error is accounted for, and the sum of these two terms in quadrature gives the total radiometric uncertainty for the instrument. This total radiometric error then takes into account the NESR, as well as the significant principal sources of expected FTIR ordinate error listed by Birch and Clarke (1995); a full description of how this is characterised can be found in Wilson et al. (1999). For example at $4.6 \mu \mathrm{m}$, sampling at $0.2 \mathrm{~Hz}$, the NESR is $2.43 \mathrm{nW} /\left(\mathrm{cm}^{2} \mathrm{sr} \mathrm{cm}^{-1}\right)$ and the blackbody calibration error is $2.10 \mathrm{nW} /\left(\mathrm{cm}^{2} \mathrm{srcm}^{-1}\right)$, thereby giving a total radiometric error of $3.21 \mathrm{nW} /\left(\mathrm{cm}^{2} \mathrm{srcm}^{-1}\right)$.

\subsection{Data filtering}

Before the retrieval of atmospheric parameters is attempted from ARIES measured spectra, poor quality spectral data (e.g. instrumental and software artefacts such as pointing error or position of zero path difference) or poor quality scenes (e.g. the presence of clouds) are removed. During this Level$1 \mathrm{~b}$ processing, a quality index is produced by the ARIES Calibration Engine (ACE) software (as used by Wilson et al., 1999, for example) for each calibrated ARIES spectrum, determined as a penalty function subtracted from $100 \%$. Key metrics such as hot and cold black body calibration statistics, phase correction, and other housekeeping parameters are used to ensure well-calibrated radiance spectra for retrievals.

Data are filtered to ensure that natural changes in the viewed scene do not exceed values pre-determined to manifest as a significant source of error in the final retrieval (greater than $\sim 0.1 \%$ of the column-mean retrieved parameter). These thresholds include surface elevation and homogeneity over the ground track of the aircraft during the acquisition time of the spectral data. We also discard spectra that were measured during a significant change in configuration of the FAAM aircraft (i.e. deviations in roll and pitch angle and/or aircraft altitude over the selected integration time), as the resulting change in atmospheric path length relative to true nadir might result in significant systematic error. To this end, thresholds for aircraft configuration have been chosen such that any difference in path length was less than $0.02 \%$. These thresholds are a roll angle of less than $5^{\circ}$, a pitch angle of between 4 and $7.5^{\circ}$, and a standard deviation of aircraft altitude of no more than $20 \mathrm{~m}$ (across the $5 \mathrm{~s}$ acquisition time). Furthermore, thresholds for the homogeneity of surface elevation for each viewed scene are calculated using a global $1 \mathrm{~km}$ digital elevation map (USGS, 1998); if the variability across the scene is greater than $20 \mathrm{~m}$ then it is not re- trieved, thereby restricting our retrievals to topographically self-consistent scenes.

Atmospheric scenes that contain clouds pose a problem to retrievals, as even partially cloudy scenes can greatly perturb infrared radiative transfer. Therefore, we attempt to remove all cloud-contaminated scenes from the retrieval product. The cloud filter algorithm employed here is a modified form of that used by Strabala et al. (1994), which examines the 8 minus $11 \mu \mathrm{m}$ brightness temperature difference. In this study a threshold difference of $1 \mathrm{~K}$ was found to be appropriate when compared to known cloudy scenes from other aircraft observations (not shown). This value is different from the $-0.4 \mathrm{~K}$ employed by Strabala et al. (1994), for satellite measurement and accounts for differences resulting from the stratospheric column (principally due to $\mathrm{H}_{2} \mathrm{O}$ emission in the stratosphere). The first cloud-free ARIES spectra either side of a detected cloud is also removed, to reduce for the potential for scattering of radiation into the FOV from clouds just outside of it.

\section{Retrieval methodology}

In this section, we discuss the maximum a posteriori method and radiative transfer model set-up chosen for ARIES retrievals. We also discuss the construction of the a priori information and a posteriori error calculation.

\subsection{Solving the inverse problem}

The MARS is an adaptation of the University of Leicester IASI Retrieval Scheme (ULIRS), described by Illingworth et al. (2011). In that study, ULIRS was described and validated for whole-atmosphere, coarse-vertical-resolution, $\mathrm{CO}$ concentration profiles. These were retrieved from top-ofatmosphere (TOA) mid-infrared radiances measured by the polar-orbiting, nadir-viewing, IASI satellite instrument.

The radiation measured by ARIES is the sum of the upward infrared radiation from the Earth (which depends on $T_{\mathrm{S}}$ and $\varepsilon_{\mathrm{S}}$, and is attenuated throughout the atmosphere by a large variety of atmospheric constituents), the emission by the atmosphere, and a back-scattered solar component. The maximum a posteriori method attempts to determine which of these properties have changed from a starting assumption, and by how much, in order to reproduce the signal that has been observed whilst simultaneously minimising a cost function based on expected constraints on those parameters.

For a discretised atmosphere, the analytical relationship between the measured radiance $\boldsymbol{y}$ and the true atmospheric state $\boldsymbol{x}$, is given by

$\boldsymbol{y}=\mathbf{F}(\boldsymbol{x} ; \boldsymbol{b})+\boldsymbol{\epsilon}$,

where the forward function $\mathbf{F}$ describes the complete physics of the measurement, the error terms are represented by $\boldsymbol{\epsilon}$, and the vector of parameters $\boldsymbol{b}$ represents all of the other fixed 
(auxiliary) parameters that have an impact on the measurement, but are not contained within the state vector. These are termed the forward function parameters, typical examples of which are the Instrument Line Shape (ILS) and the unobserved parameters of the atmospheric state.

In order to determine the state vector (a best representation of the atmospheric state) from the measurement, the solution to Eq. (1) needs to be inverted. The maximum a posteriori method regularises this inversion with a priori information about the variables to be retrieved; for a complete theoretical formulation of the maximum a posteriori method see Rodgers (2000). This a priori information consists of a mean prior state $\boldsymbol{x}_{\mathrm{a}}$ and an a priori covariance matrix $\mathbf{S}_{\mathrm{a}}$, which represents statistical knowledge on the variability of the true state around $\boldsymbol{x}_{\mathrm{a}}$ that exists for the state prior to any measurement. The formulation of these statistical constraints is discussed further in Sect. 4.2. As discussed above, the maximum a posteriori method works by essentially minimising a function that includes both measurement and prior information about the state of the atmosphere. This function is known as the joint cost function, and it can be expressed as

$$
\begin{aligned}
\chi^{2} & =(\boldsymbol{y}-\mathbf{F}(\hat{\boldsymbol{x}}))^{T} \mathbf{S}_{y}^{-1}(\boldsymbol{y}-\mathbf{F}(\hat{\boldsymbol{x}})) \\
& +\left(\hat{\boldsymbol{x}}-\boldsymbol{x}_{\mathbf{a}}\right)^{T} \mathbf{S}_{\mathbf{a}}^{-1}\left(\hat{\boldsymbol{x}}-\boldsymbol{x}_{\mathbf{a}}\right),
\end{aligned}
$$

where $\hat{\boldsymbol{x}}$ is the retrieved state vector, and $\mathbf{S}_{y}$ is the measurement noise covariance matrix. The expectation of $\chi^{2}$ over a large number of retrievals is equal to the number of measurements $m$, the total number of degrees of freedom. This number has two components: the Degrees of Freedom for Signal (DOFS) and the Degrees of Freedom for Noise (DOFN), and it is the DOFS term which describes the number of independent pieces of information in the state vector that have been determined from measurement, and that have not come solely from the a priori information. This can be thought of as a relative measure for the vertical sensitivity or pieces of information about the vertical profile.

The retrieval scheme for the ARIES measurements uses tailored Exelis Visual Information Solutions IDL software and v4.3 of the reference forward model (RFM), a line-byline radiative transfer (RT) model (Dudhia, 2000), to calculate the Jacobians $(\partial \mathbf{F} / \partial \mathbf{x})$ that are required for the minimisation of the joint cost function, which is then iterated until specified convergence criteria are met (see below). The RFM was developed at Oxford University in the UK, and is based on the GENLN2 RT model (Edwards, 1992). It includes a term for the atmospheric emission reflected by the Earth's surface, modelling this reflection as specular, and can be operated for any spectral range between 0.001 and $20000 \mathrm{~cm}^{-1}$ $(10 \mathrm{~m}$ to $0.5 \mu \mathrm{m})$ at a spectral fine grid sampling of 0.0005 to $1.0 \mathrm{~cm}^{-1}$. Version 4.3 of the RFM utilises the updated 2012 HITRAN database (Rothman et al., 2013).

In this study, it was observed that back-scattered solar radiation was significant only when modelling spectral subranges (commonly referred to as retrieval micro-windows)
Table 2. List of the spectral windows used for the retrieval of gases and temperature. References from which these regions were taken are also included.

\begin{tabular}{lrr}
\hline $\begin{array}{l}\text { Retrieval } \\
\text { product }\end{array}$ & $\begin{array}{r}\text { Spectral } \\
\text { window }\left(\mathrm{cm}^{-1}\right)\end{array}$ & Reference \\
\hline$T$ & $690-775$ & $\begin{array}{r}\text { Chedin et al. (2003) } \\
\mathrm{H}_{2} \mathrm{O}\end{array}$ \\
$\mathrm{CH}_{4}$ & $1200-1410$ & Schneider and Hase (2011) \\
$\mathrm{O}_{3}$ & $1240-1290$ & Razavi et al. (2009) \\
$\mathrm{CO}$ & $990-1040$ & Boynard et al. (2009) \\
\hline
\end{tabular}

of wavelength less than $5 \mu \mathrm{m}$, consistent with that reported by Houghton et al. (1986). At these wavelengths, the backscattered solar component is calculated as in Illingworth et al. (2011), with the solar radiance incident on the Earth determined from the Atmospheric Chemistry Experiment (ACE) FTS atlas of the infrared solar spectrum (Hase et al., 2010), the optical depth of the atmosphere calculated using the RFM, and the surface albedo determined from the scene emissivity. Because of the particle size of atmospheric aerosols, a reasonable assumption is to ignore scattering effects in the thermal infraRed (TIR). In this study atmospheric scattering effects are not considered.

The MARS employs a Levenberg-Marquardt iterative technique, which makes use of a damping factor $\lambda$, chosen to minimise the cost function at each step of the iteration. An initial damping factor of 0.1 is selected, then after every iteration the cost function is calculated, and compared to the cost function of the previous iteration. If there has been an increase in the cost function then the damping factor is increased by a factor of 8 , and if there has been a reduction in the cost function, then the damping factor is reduced by a factor of 4 . The iteration process is stopped either when the relative variation of the change in cost function is less than a factor of 0.001 , or when no convergence is reached within 15 iterations, in which case the retrieval is classified as unsuccessful. On average more than $99 \%$ of retrievals were classified as successful in this manner.

Spectral retrieval windows for individual gases and parameters were chosen here from previous (satellite) studies of retrievals in the TIR as shown in Table 2.

The instrument noise spectral covariance matrix $\mathbf{S}_{y}$ was constructed from two other covariance matrices: a diagonal matrix constructed from the NESR, where the errors in any singular channel were assumed to be independent of other channels; and a non-diagonal matrix computed from consecutive calibration differences. The NESR diagonal matrix was first divided by the square root of the number of co-added measured spectra (five in this case, as described in Sect. 3.1). Typical values for the noise are given later in the paper (for example Tables 3-6 and Figs. 1b and $2 \mathrm{~b}$ ), and range from $2.04 \mathrm{nW} /\left(\mathrm{cm}^{2} \mathrm{srcm}^{-1}\right)$ in the $\mathrm{CO}$ spectral region to $98.34 \mathrm{nW} /\left(\mathrm{cm}^{2} \mathrm{srcm}^{-1}\right)$ in the spectral 
Table 3. Summary of simulated retrievals for a European background climatology, at $7 \mathrm{~km}$ flight altitude. From left to right, columns 2 and 3 show mean differences between retrieved and smoothed truth, and retrieved and true profiles, respectively. Standard deviation ( $\sigma)$ of the biases is given in brackets. The fourth column shows the mean difference between a priori and true profiles. Further columns show the mean DOFS, spectral residual, and measurement noise. The error represents the mean a posteriori error for the column. Err. red represents the mean error reduction. Iterations is the average number of iterations that were required for convergence.

\begin{tabular}{lrrrrrrrrr}
\hline Gas & $\hat{\boldsymbol{x}}-\boldsymbol{x}_{t}^{*}$ & $\hat{\boldsymbol{x}}-\boldsymbol{x}_{t}$ & $\boldsymbol{x}_{\mathrm{a}}-\boldsymbol{x}_{t}$ & DOFS & Residual & Noise & Error & Err. red. & Iterations \\
\hline & & & & & $\mathrm{nW} /\left(\mathrm{cm}^{2}\right.$ & $\mathrm{nW} /\left(\mathrm{cm}^{2}\right.$ & & & \\
Units & $\%$ & $\%$ & $\%$ & Unitless & $\left.\mathrm{srcm}^{-1}\right)$ & $\left.\mathrm{srcm}^{-1}\right)$ & $\%$ & $\%$ & Unitless \\
\hline$T$ & $0.05(0.02)$ & $0.14(0.02)$ & 1.11 & 3.94 & 24.47 & 103.66 & 0.20 & 68.69 & 4 \\
$\mathrm{H}_{2} \mathrm{O}$ & $3.95(3.11)$ & $6.76(3.33)$ & 10.0 & 2.71 & 13.39 & 46.62 & 22.57 & 50.36 & 2.86 \\
$\mathrm{CO}$ & $3.07(1.36)$ & $2.88(1.38)$ & 2.98 & 0.85 & 1.48 & 3.21 & 18.22 & 16.13 & 2 \\
$\mathrm{O}_{3}$ & $4.87(4.76)$ & $-10.92(0.74)$ & -26.08 & 0.96 & 13.92 & 53.49 & 14.76 & 16.32 & 4.72 \\
$\mathrm{CH}_{4}$ & $1.42(1.36)$ & $-0.50(1.33)$ & -4.56 & 1.37 & 14.78 & 48.83 & 16.42 & 24.61 & 2.44 \\
\hline
\end{tabular}

Table 4. Same as Table 3, but for a biomass burning climatology at a simulated altitude of $7 \mathrm{~km}$.

\begin{tabular}{lrrrrrrrrr}
\hline Gas & $\hat{\boldsymbol{x}}-\boldsymbol{x}_{t}^{*}$ & $\hat{\boldsymbol{x}}-\boldsymbol{x}_{t}$ & $\boldsymbol{x}_{\mathrm{a}}-\boldsymbol{x}_{t}$ & DOFS & Residual & Noise & Error & Err. red. & Iterations \\
\hline & & & & & $\mathrm{nW} /\left(\mathrm{cm}^{2}\right.$ & $\mathrm{nW} /\left(\mathrm{cm}^{2}\right.$ & & & \\
Units & $\%$ & $\%$ & $\%$ & Unitless & $\left.\mathrm{sr} \mathrm{cm}^{-1}\right)$ & $\left.\mathrm{srcm}^{-1}\right)$ & $\%$ & $\%$ & Unitless \\
\hline$T$ & $0.06(0.02)$ & $0.16(0.02)$ & 1.09 & 3.99 & 25.98 & 103.66 & 0.19 & 68.85 & 4 \\
$\mathrm{H}_{2} \mathrm{O}$ & $2.06(2.74)$ & $4.55(2.89)$ & 10.0 & 2.97 & 13.36 & 46.62 & 21.35 & 54.02 & 2.94 \\
$\mathrm{CO}$ & $-0.06(7.53)$ & $-35.08(0.61)$ & -46.37 & 0.71 & 1.61 & 3.21 & 9.22 & 14.12 & 3.10 \\
$\mathrm{O}_{3}$ & $2.19(0.50)$ & $-8.30(0.47)$ & -1.49 & 0.78 & 14.58 & 53.49 & 7.07 & 14.11 & 3 \\
$\mathrm{CH}_{4}$ & $0.77(1.40)$ & $0.68(2.57)$ & -3.39 & 1.45 & 14.17 & 48.83 & 16.09 & 26.28 & 2.26 \\
\hline
\end{tabular}

Table 5. Same as Table 3, but for a European background climatology at a simulated altitude of $2 \mathrm{~km}$.

\begin{tabular}{lrrrrrrrrr}
\hline Gas & $\hat{\boldsymbol{x}}-\boldsymbol{x}_{t}^{*}$ & $\hat{\boldsymbol{x}}-\boldsymbol{x}_{t}$ & $\boldsymbol{x}_{\mathrm{a}}-\boldsymbol{x}_{t}$ & DOFS & Residual & Noise & Error & Err. red. & Iterations \\
\hline & & & & & $\mathrm{nW} /\left(\mathrm{cm}^{2}\right.$ & $\mathrm{nW} /\left(\mathrm{cm}^{2}\right.$ & & & \\
Units & $\%$ & $\%$ & $\%$ & Unitless & $\left.\mathrm{sr} \mathrm{cm}^{-1}\right)$ & $\left.\mathrm{srcm}^{-1}\right)$ & $\%$ & $\%$ & Unitless \\
\hline$T$ & $0.04(0.02)$ & $0.11(0.02)$ & 1.05 & 2.55 & 17.67 & 103.66 & 0.10 & 90.00 & 5 \\
$\mathrm{H}_{2} \mathrm{O}$ & $3.28(3.14)$ & $5.25(3.31)$ & 10.0 & 1.61 & 12.92 & 46.62 & 18.35 & 61.65 & 3 \\
$\mathrm{CO}$ & $3.74(2.97)$ & $0.13(2.89)$ & -1.34 & 0.49 & 1.49 & 3.21 & 16.72 & 25.18 & 2.10 \\
$\mathrm{O}_{3}$ & $-8.26(4.64)$ & $-34.25(2.38)$ & -36.04 & 0.32 & 13.37 & 53.49 & 17.61 & 15.59 & 2.61 \\
$\mathrm{CH}_{4}$ & $3.01(2.61)$ & $0.68(2.57)$ & -5.75 & 0.83 & 14.69 & 48.83 & 13.47 & 41.21 & 2.68 \\
\hline
\end{tabular}

Table 6. Same as Table 3, but for a biomass burning climatology at a simulated altitude of $2 \mathrm{~km}$.

\begin{tabular}{lrrrrrrrrr}
\hline Gas & $\hat{\boldsymbol{x}}-\boldsymbol{x}_{t}^{*}$ & $\hat{\boldsymbol{x}}-\boldsymbol{x}_{t}$ & $\boldsymbol{x}_{\mathrm{a}}-\boldsymbol{x}_{t}$ & DOFS & Residual & Noise & Error & Err. red. & Iterations \\
\hline & & & & & $\mathrm{nW} /\left(\mathrm{cm}^{2}\right.$ & $\mathrm{nW} /\left(\mathrm{cm}^{2}\right.$ & & & \\
Units & $\%$ & $\%$ & $\%$ & Unitless & $\left.\mathrm{sr} \mathrm{cm}^{-1}\right)$ & $\left.\mathrm{srcm}^{-1}\right)$ & $\%$ & $\%$ & Unitless \\
\hline$T$ & $0.03(0.02)$ & $0.12(0.02)$ & 1.03 & 2.43 & 17.20 & 103.66 & 0.11 & 88.53 & 4.4 \\
$\mathrm{H}_{2} \mathrm{O}$ & $3.25(2.53)$ & $5.57(2.68)$ & 10.0 & 1.61 & 13.28 & 46.62 & 18.02 & 62.50 & 2.98 \\
$\mathrm{CO}$ & $-2.88(1.52)$ & $-47.36(0.64)$ & -62.95 & 0.39 & 2.70 & 3.21 & 7.86 & 19.67 & 4.04 \\
$\mathrm{O}_{3}$ & $-1.62(2.54)$ & $-22.92(0.46)$ & -24.68 & 0.18 & 15.86 & 53.49 & 5.85 & 8.38 & 2.14 \\
$\mathrm{CH}_{4}$ & $2.11(1.99)$ & $-1.09(1.86)$ & -6.09 & 0.86 & 13.93 & 48.83 & 13.35 & 41.28 & 2.82 \\
\hline
\end{tabular}


region used to retrieve temperature (see Table 2). In comparison, measurement noise for the IASI instrument is around $20 \mathrm{nW} /\left(\mathrm{cm}^{2} \mathrm{sr} \mathrm{cm}^{-1}\right)$ at $1000 \mathrm{~cm}^{-1}$ (Clerbaux et al., 2009).

\subsection{Simulated atmosphere and constraints}

In this section we describe the construction of the simulated atmosphere, the retrieval state vectors and their a priori, the auxiliary (non-retrieved) gases and the rationale behind their constraints.

\subsubsection{The vertical grid and thermodynamic scaling}

For reasons outlined in Deeter et al. (2007b), the vertical retrieval grid used in the retrieval algorithm was chosen to consist of a fixed number of pressure levels with isobaric spacing, varying between the surface pressure (as extracted from ECMWF data, see Sect. "Thermodynamic state and surface properties") and the aircraft-measured pressure of the atmosphere at flight level. Isobaric spacing ensures that each layer contains a similar mass of air, therefore leading to a more efficient interpretation of the Jacobians. For an altitude of $7 \mathrm{~km}$ or higher, it was found that 10 equidistant pressure levels were sufficient to fully characterise vertical sensitivity for the parameters here. The number of levels employed is commensurately reduced at lower flight altitudes, reducing linearly from 10 to 2 levels between 7 and $1 \mathrm{~km}$. As well as significantly improving the computational efficiency, sensitivity studies showed that the difference in the spectral residual between representing the atmosphere in either 30 or 10 discrete levels in the forward model is significantly less than the noise of the ARIES instrument.

\subsubsection{A priori data and state parameters}

The auxiliary gases are defined as those gases that are not retrieved, but that exhibit significant spectral features in the chosen spectral window. Due to differing retrieval microwindows this list of auxiliary gases was necessarily different for each of the retrieval parameters. However, in the construction of the state vector, $\boldsymbol{x}$, it was decided that as well as the target gas, the retrieval of $\mathrm{H}_{2} \mathrm{O}$, temperature, and aerosol extinction profiles, as well as $T_{\mathrm{s}}$, were also always operationally required. However, it should be clarified that for each of the target gases (and temperature) to be retrieved, a separate state vector is constructed (e.g. CO is not retrieved simultaneously with $\mathrm{O}_{3}$ ).

\section{Thermodynamic state and surface properties}

An ECWMF T159 resolution $\left(1.125^{\circ} \times 1.125^{\circ}\right.$ grid on 91 model levels) operational reanalysis data set was used for the construction of $\boldsymbol{x}_{\mathrm{a}}$ for $\mathrm{H}_{2} \mathrm{O}$, surface pressure and temperature. The geolocated ECMWF profiles were first linearly interpolated onto the same vertical pressure grid as those used in the retrieval, before a further horizontal (sub-grid spatial) bilinear interpolation was performed.

For the joint retrieval of $\mathrm{H}_{2} \mathrm{O}$ and temperature, when being retrieved within the state vector of a trace gas, the $\mathbf{S}_{\mathrm{a}}$ is constructed as follows. The square root of the diagonal elements of $\mathbf{S}_{\mathrm{a}}$ corresponding to $\mathrm{H}_{2} \mathrm{O}$ and temperature are set to $10 \%$ of the ECMWF $\mathrm{H}_{2} \mathrm{O}$ profile and $1 \mathrm{~K}$, respectively, with the off-diagonal elements calculated using the following equation:

$\mathbf{S}_{i j}=\sqrt{\mathbf{S}_{i i} \mathbf{S}_{j j}} \exp \left(\frac{-\left(\mathbf{z}_{i}-\mathbf{z}_{j}\right)^{2}}{z_{\mathrm{s}}^{2}},\right)$

where $\mathbf{z}_{i}$ and $\mathbf{z}_{j}$ are the altitudes of the $i$ th and $j$ th elements of the profile, and $z_{\mathrm{s}}$ is a smoothing length, which was set at $1 \mathrm{~km}$ in both cases. These values (the diagonal elements of $\mathbf{S}_{\mathrm{a}}$ and the smoothing length) have been chosen to be consistent with the background error standard deviation assumed for the ECMWF data assimilation (Fillion and Mahfouf, 2000).

For the initial $T_{\mathrm{s}}$, the surface temperature retrieved by the Heimann infrared thermometer on board the FAAM aircraft is used where available, with the value of $\mathbf{S}_{\mathrm{a}}$ typically fixed at $25 \mathrm{~K}^{2}$ to allow for an expected, potentially large, natural variability in the surface environment, whilst also accounting for potential uncertainty in the Heimann measurements. The Heimann KT 19.82 instrument derives upwelling brightness temperature, measured over the spectral range 8-14 $\mu \mathrm{m}$. Where such data may not be available (due to instrument maintenance, or poor performance), the lowest value of the ECMWF temperature profile is used instead. In some circumstances this use of the lowest ECWMF atmospheric temperature measurement for $T_{\mathrm{s}}$ can lead to anomalous results, with the 6-hourly resolution of ECMWF operational data meaning that the assumed $T_{\mathrm{S}}$ could be significantly different from the actual $T_{\mathrm{S}}$ at times of large gradients to surface heating and cooling (e.g. early morning or late evening). This potential difference is compensated for here by allowing the a priori variability for $T_{\mathrm{s}}$ to be reasonably large $(1 \sigma=5 \mathrm{~K})$.

The separate treatment of $\varepsilon_{\mathrm{s}}$ and $T_{\mathrm{S}}$ in the chosen spectral window is not possible because of the nonlinearity of the relationship between radiance and surface temperature. Therefore it is necessary here that we use a fixed emissivity for the viewed scene that is as representative of the true emissivity as possible. In its calculation of a suitable term for $\varepsilon_{\mathrm{s}}$, the MARS utilises the University of Wisconsin Baseline Fit Emissivity database described by Seemann et al. (2008), which is defined by a spatial resolution of $0.05^{\circ}$, a monthly temporal resolution, and a spectral resolution of $\sim 5 \mathrm{~cm}^{-1}$.

\section{Aerosol}

Aerosol in the atmosphere presents a distinct problem for retrievals at all wavelengths, having the potential to scatter, absorb and re-emit radiation. Such effects are difficult to accurately quantify due to natural variability in aerosol type 
and concentration and an inherent highly variable refractive index. This may be especially problematic in regimes such as when viewing through the urban boundary layer or over desert and volcanic dust outflows. Many operational retrieval schemes used by satellites, such as those employed for the IASI Level 2 standard product (August et al., 2012), assume that no aerosol is present. This assumption may preclude a potential wealth of additional useful composition information relating to aerosol speciation and the global energy budget (through effects on infrared radiative transfer). Recent work by Clarisse et al. (2012), discusses such a capability from infrared nadir sounding and shows promise. We characterise and account for aerosol absorption effects on our retrievals in this work but an analysis of sensitivity to aerosol composition is beyond the scope of this study.

Aerosol can be thought of as an optically thin grey body, radiating (and scattering) at the temperature of the vertical layer it exists within. This would suggest that retrieval schemes that ignore aerosol may be subject to sources of unquantified systematic temperature bias (as noted for IASI by Quan et al., 2012), with consequent unquantified uncertainties for trace gas retrievals. While the RFM line-by-line model used here cannot treat scattering, we can simulate the impacts of aerosol extinction and therefore make an attempt to simulate its impacts on our observations and account for its presence in the atmosphere. Aerosol is highly variable, spanning several orders of magnitude in terms of number and mass concentration and hence extinction. We reflect this variability in our a priori constraint, which has been chosen to carefully capture expected natural variability whilst not forcing the algorithm to model aerosol at the expense of temperature. The square root of the diagonal elements of $\mathbf{S}_{\mathrm{a}}$ are set to $100 \%$ of an arbitrary a priori value, and the off-diagonals are calculated using Eq. (3) and a smoothing length of $1 \mathrm{~km}$, as described for temperature and $\mathrm{H}_{2} \mathrm{O}$ in Sect. "Thermodynamic state and surface properties". We use a wavelength-independent simulated aerosol extinction profile, which ranges from $0.00075 \mathrm{~km}^{-1}$ at the surface to $0.00035 \mathrm{~km}^{-1}$ at $7 \mathrm{~km}$. It was found that by not including aerosol as a state parameter, the error on the retrieved temperature could be increased by as much as $0.4 \mathrm{~K}$.

\section{Parameter gases}

A priori information for the target gas (or gases) is constructed using data compiled by the Monitoring Atmospheric Composition and Change (MACC) project described by Inness et al. (2013). The MACC atmospheric profiles are available on 25 pressure levels, ranging from 1000 to $1 \mathrm{hPa}$, on a $1.125^{\circ} \times 1.125^{\circ}$ global grid, with daily temporal resolution. In the retrievals discussed in this study, these profiles are averaged onto a $5^{\circ} \times 5^{\circ}$ grid, and linearly interpolated onto the retrieval pressure levels.
A single profile of $\boldsymbol{x}_{\mathrm{a}}$ is used for each flight for consistency. This climatological profile is constructed in operational retrievals by averaging the MACC data set over a region bounded by the flight track for a specified temporal range. The construction of $\mathbf{S}_{\mathrm{a}}$ has a large effect on the retrieval process, and must be chosen carefully to maximise the information content, whilst allowing for the retrieval to be suitably constrained. It is not unreasonable to select a broader $\mathbf{S}_{\mathrm{a}}$ for some trace gases in the case of aircraft sampling, than might be calculated from global climatologies that are often assumed for random global sampling by satellites. This is because aircraft sampling often targets enhancements or specific regions of interest. With this non-random sampling in mind, the choice of $\boldsymbol{x}_{\mathrm{a}}$ and $\mathbf{S}_{\mathrm{a}}$ needs to be tailored to the specific campaign or flight.

\subsubsection{Auxiliary gases}

A set of reference climatologies compiled by Remedios et al. (2007b) is used to represent the weakly absorbing auxiliary gases in the forward model. The choice of auxiliary gases is determined here by calculating the relative optical strength (nominally defined as $15+\log _{10}$ (max optical depth)). Gases with an optical strength of less than $0.1 \%$ that of the target gas, and/or a radiance contribution to the total spectrum peaking below the nominal instrumental noise in that region (see Tables 3-6), were found to have a negligible impact and were not included in the simulated atmosphere.

\subsection{A posteriori error formulation}

The forward model parameter error for each of the trace gases, is calculated for each retrieval, along with a smoothing, measurement, and systematic error, following the methodology outlined for a linear approach by Rodgers (2000). Here the smoothing error represents the loss of fine structure in the retrieved state. The measurement error is derived from the total radiometric error of the ARIES instrument, and the parameter error is associated with the nonretrieval of the auxiliary gases. The systematic error is derived from the Level-1b processing as described in Sect. 3.1.

\section{Retrieval simulations}

In the remainder of this study, we assess the potential in principle to retrieve accurate information from simulated ARIES spectra for known true states in a range of simulated environments (e.g. clean and polluted). This assessment will take the form of a series of simulations, in which pseudo-ARIES spectra are used to retrieve target information. Retrievals are then examined a posteriori for sources of error, systematic bias (defined here as the difference between the retrieved and true state); and overall information content and vertical sensitivity. We note that the dashed black lines labeled as the "noise" in, for example, Fig. 1b represent a total uncertainty, 

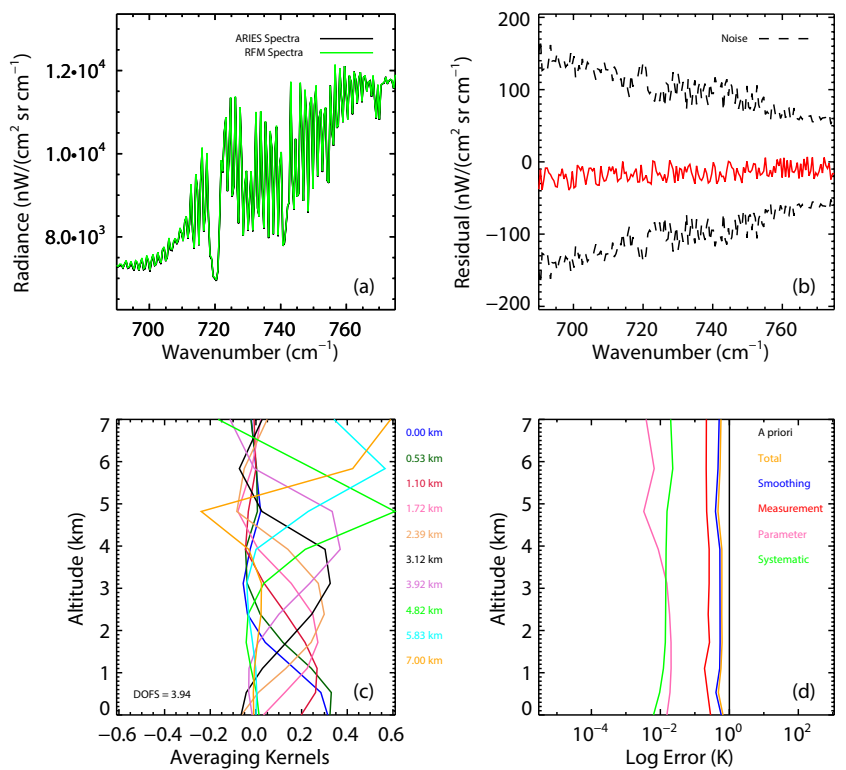

Fig. 1. Typical retrieval metrics for the retrieval of temperature from simulated spectra, for an altitude of $7 \mathrm{~km}$ : (a) simulated (ARIES) and retrieved (RFM) spectra, (b) residual difference between ARIES and RFM spectra, (c) averaging kernels for retrieval, and (d) a priori and a posteriori errors.

that is, the sum of the random (Gaussian) noise and the radiometric uncertainty (a potential bias derived from consecutive calibration differences). In the simulations we add random noise to the simulated spectrum but we do not add a radiometric uncertainty (which is implicit to the temperature uncertainty we discuss in Sect. 5.1) At wavelengths $\sim 10 \mu \mathrm{m}$, the radiometric uncertainty dominates over the random noise and so for simulations in this spectral region (e.g. Figs. 1b and $2 b$ ), one could expect the simulated residual to be smaller than the indicated uncertainty envelope (which includes the additional radiometric uncertainty). Across the spectral range of the ARIES instrument used in the simulations (Table 2) the maximum value of the random and systematic components of the noise are 70 and $169 \mathrm{nW} /\left(\mathrm{cm}^{2} \mathrm{srcm}^{-1}\right)$, respectively.

\subsection{Formulation of simulations and sensitivities}

Daytime conditions were chosen for the simulations, to investigate the efficacy of the solar reflected component described in Sect. 4.1. For retrievals that incorporate a backscattered solar component, part of this term will depend on the state of the atmosphere above the aircraft, for which the reference profiles of Remedios et al. (2007b) have been used. The importance of this potential sensitivity to the composition above the aircraft depends on $\varepsilon_{\mathrm{s}}$. For $\mathrm{CO}$, which is retrieved over a spectral window between 4.59 and $4.67 \mu \mathrm{m}$ (2143 to $2181 \mathrm{~cm}^{-1}$, see Table 2), the back-scattered solar component is significant and must be taken into account. A solar zenith angle of $40^{\circ}$, typical of noon in the mid-latitudes,
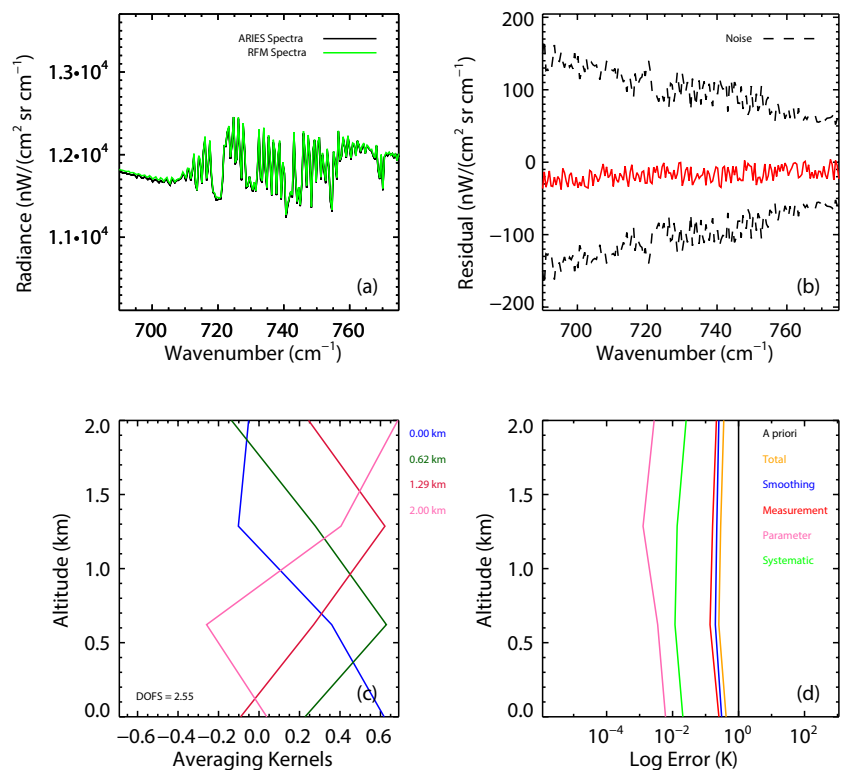

Fig. 2. Typical retrieval metrics for the retrieval of temperature from simulated spectra, for an altitude of $2 \mathrm{~km}$ : (a) simulated (ARIES) and retrieved (RFM) spectra; (b) residual difference between ARIES and RFM spectra; (c) averaging kernels for retrieval; (d) a priori and a posteriori errors.

was chosen. For a $\varepsilon_{\mathrm{S}}$ of 0.85 (typically representative of a desert in the TIR to maximise the potential albedo), a ground elevation of $0 \mathrm{~m}$, and an altitude of $7 \mathrm{~km}$, for a typical European CO climatology, two retrievals were simulated to test sensitivity: one where the $\boldsymbol{x}_{\mathrm{a}}$ above the aircraft was set equal to the reference profiles of Remedios et al. (2007b); and one where an arbitrary $+10 \%$ offset was applied. The difference between the retrieved partial columns in the nadir was negligible (less than $0.1 \%$ ), confirming that any potential uncertainty about the atmosphere above the aircraft would result in a negligible bias in the nadir retrievals.

The $\mathbf{S}_{y}$ was created following the method outlined in Sect. 4.1 using instrument calibration information from FAAM Flight B290 on 30 April 2007 (Larar et al., 2010) as a typical example.

For each of the retrieval products a true atmospheric profile was simulated using climatological data from the CAMELOT (Chemistry of the Atmosphere Mission concEpts and sentineL Observations Techniques) study (Levelt et al., 2009). Two different CAMELOT profiles were chosen, representing typical European Background (EB) and tropical biomass burning (BB) conditions. Simulations were then carried out at 7 and $2 \mathrm{~km}(\sim 400 \mathrm{hPa}$, and $\sim 795 \mathrm{hPa}$, respectively) which were chosen to give a broad representation of the type of environment in which the ARIES typically operates. For the 7 and $2 \mathrm{~km}$ scenarios, 10 and 4 equidistant pressure levels were used, respectively. A surface elevation of $0 \mathrm{~m}$ was chosen, and $\varepsilon_{\mathrm{s}}$ was set to 0.974 for the EB and 0.965 for the BB scenarios. 
For each of the retrieval products, the RFM simulated spectra at the observer altitude were convolved with a measured ARIES ILS to generate pseudo-ARIES spectra. The initial $T_{\mathrm{s}}$ was set equal to the lowest CAMELOT atmospheric temperature, resulting in a surface thermal contrast of zero. This represents a minimum in sensitivity towards the near surface.

A simulated random noise component was added using the typical noise values given in Tables 3-6. A retrieval was then performed and compared with the known true profile. Even for a perfect retrieval scheme (i.e. one for which there is no source of error apart from that introduced by discretising the simulated atmosphere), the retrieved state vector will not usually be equal to the true state vector: $\hat{\boldsymbol{x}} \neq \boldsymbol{x}_{t}$. This is because of the smoothing that has been introduced by the limited resolution of the retrieval. For a perfect retrieval (i.e. one in which there is no bias), $\boldsymbol{x}_{t}^{*}$ can be defined as

$x_{t}^{*}=\boldsymbol{x}_{\mathrm{a}}+\mathbf{A}\left(\boldsymbol{x}_{t}-\boldsymbol{x}_{\mathrm{a}}\right) \neq \boldsymbol{x}_{t}$,

where A represents the ARIES averaging kernel; furthermore, in the absence of any errors, $\hat{\boldsymbol{x}}=\mathbf{x}_{t}^{*}$. This smoothing accounts for the vertical resolution of the retrieval and removes any differences that may manifest from the choice of $\boldsymbol{x}_{\mathrm{a}}$ and $\mathbf{S}_{\mathrm{a}}$. This convolution of the true profile is necessary so that a like-for-like comparison can be made in the assessment of any systematic retrieval bias (see e.g. Rodgers and Connor, 2003; Worden et al., 2013). Thus, by comparing $\hat{\boldsymbol{x}}$ with $\mathbf{x}_{t}^{*}$ we are able to assess how the MARS performs in principle, while comparing $\hat{\boldsymbol{x}}$ with $\boldsymbol{x}_{t}$ (and comparing this to $\boldsymbol{x}_{\mathrm{a}}$ ) allows us to assess the performance of MARS in retrieving the true state of the atmosphere (and any improvement relative to the a priori).

For all simulations here, $\boldsymbol{x}_{\mathrm{a}}$ was constructed using MACC modelled data averaged within a $20^{\circ}$ latitude band centred on the CAMELOT profile, and across a 3-month period from April to June 2007. For $\mathrm{CO}, \mathrm{CH}_{4}$, and $\mathrm{O}_{3}, \mathbf{S}_{\mathrm{a}}$ was constructed using Eq. (3), with a smoothing length of $1 \mathrm{~km}$, and by setting the square root of the diagonal elements equal to $20 \%$ of $\boldsymbol{x}_{\mathrm{a}}$. For $\mathrm{H}_{2} \mathrm{O}$ and temperature, $\mathbf{x}_{a}$ was calculated from the CAMELOT data sets with the appropriate positive bias applied (see below), whilst $\mathbf{S}_{\mathrm{a}}$ was constructed using Eq. (3), with a smoothing length of $1 \mathrm{~km}$, and by setting the square root of the diagonal elements equal to $10 \%$ of $\boldsymbol{x}_{\mathrm{a}}$ and $1 \mathrm{~K}$, for $\mathrm{H}_{2} \mathrm{O}$ and temperature, respectively.

In order to characterise uncertainty arising from sources of instrumental radiometric error the simulations were repeated 50 times for each of the retrieval products for each of the different scenarios. An average and standard deviation of the biases (see Tables 3-6) was calculated to characterise the effect of this noise component, which was added randomly to the simulated spectra in each of the 50 simulations.

In order to test retrieval sensitivity to situations where the $\mathrm{H}_{2} \mathrm{O}$ and temperature may not necessarily be well known, $\mathrm{H}_{2} \mathrm{O}$ and temperature a priori profiles were offset from the truth by $+10 \%$ and $+0.8 \mathrm{~K}$, respectively. These values were chosen as they represented a significant (and typical) error in the meteorological data sets (i.e. ECMWF, see e.g. Engelen et al., 2001) used here to construct the a priori thermodynamics. Where temperature was the target of the simulated retrieval, a positive bias (between $\boldsymbol{x}_{t}$ and $\boldsymbol{x}_{\mathrm{a}}$ ) of $+3 \mathrm{~K}$ was introduced. When $\mathrm{H}_{2} \mathrm{O}$ was the target, $\mathbf{S}_{\mathrm{a}}$ was constructed using Eq. (3) with a smoothing length of $1 \mathrm{~km}$, and the square root of the diagonal elements was set equal to $30 \%$ of $\boldsymbol{x}_{\mathrm{a}}$.

\subsection{Results of simulations}

This section discusses the performance of the simulations for each retrieval parameter. It should be noted that on average more than $99 \%$ of retrievals were classified as successful according to the convergence criteria set out in Sect. 4.1.

\subsubsection{Temperature}

Tables 3-6 report six useful diagnostic statistics from the retrievals: the mean DOFS, the mean spectral residual, the instrumental noise; the a posteriori error, the error reduction, and the mean number of iterations necessary to reach convergence. Temperature retrievals yield much higher DOFS (maximum values of 2.6 at $2 \mathrm{~km}$ and 4.0 at $7 \mathrm{~km}$ ) compared to the trace gases (see Figs. 1c and 2c and Tables 3-6). This confirms that retrieved temperature profiles contain significant vertically resolved information that provide between 2 to 4 pieces of independent information, depending on the altitude and environment. Such information is expected to be useful for a variety of purposes, including assimilation into Numerical Weather Prediction (NWP) models. There is also an impressive improvement in the error reduction term (up to $90 \%$ ) across the temperature profile (Fig. 1d and 2d), with a posteriori errors across the profile being typically less than $0.2 \%$. Note that error reduction is defined here as the mean value of the diagonal terms of $\mathbf{I}-\left(\mathbf{S}_{\mathrm{a}} / \mathbf{S}\right)$, where $\mathbf{I}$ is an identity matrix.

Figure 3 shows that there is good agreement between both the retrieved and smoothed profiles, and the retrieved and true profiles. The largest bias between $\hat{\boldsymbol{x}}$ and $\boldsymbol{x}_{t}$ was found to be $+0.16 \%( \pm 0.02 \%$ at $1 \sigma)$ in the case of the BB scenario from $7 \mathrm{~km}$. This is a significant improvement compared to the average bias between $\boldsymbol{x}_{t}$ and $\boldsymbol{x}_{\mathrm{a}}$ of $+1.08 \%$. This is due to the independent sensitivity to discrete altitudes throughout the partial column as seen in the AKs (Figs. 1c and 2c), which includes sensitivity to the near surface.

The effect of a poor initial choice of $T_{\mathrm{S}}$ was also investigated. The simulations for the EB and $\mathrm{BB}$ scenarios at 2 and $7 \mathrm{~km}$ were repeated, but with the initial $T_{\mathrm{S}}$ set to $3 \mathrm{~K}$ greater than that of the lowest atmospheric retrieval layer. This was found to have a negligible effect on the simulations (less than $0.1 \%$ across the mean retrieved profiles) as the joint retrieval of $T_{\mathrm{S}}$ and the temperature profile accurately determines the truth for both parameters within the retrieval constraints. The choice of $3 \mathrm{~K}$ for this sensitivity test for $T_{\mathrm{S}}$ 

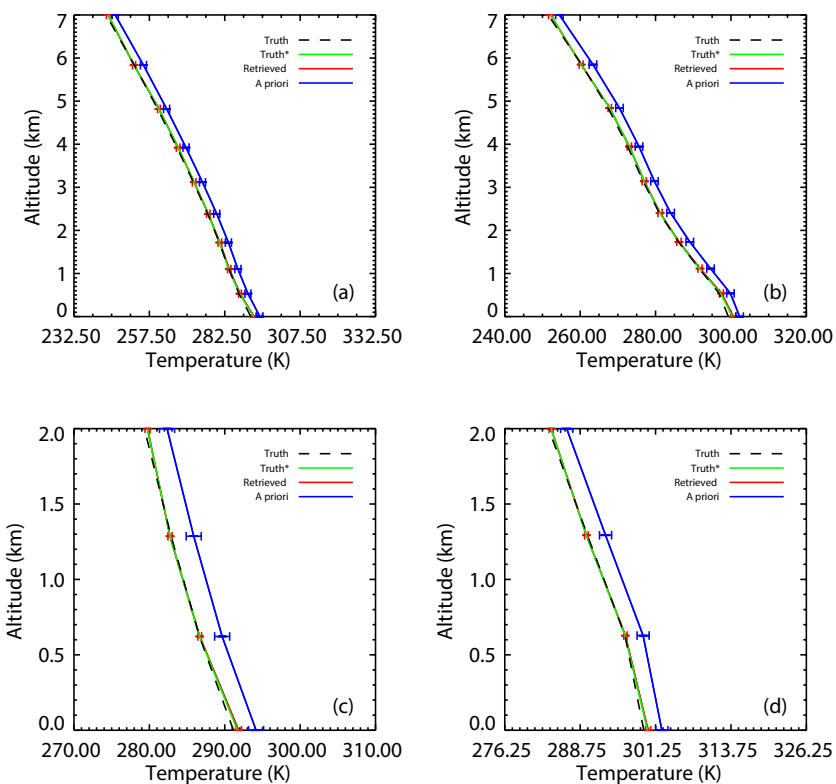

Fig. 3. (a) True $\left(\boldsymbol{x}_{t}\right)$, smoothed truth $\left(\boldsymbol{x}_{t}^{*}\right)$, retrieved $(\hat{\boldsymbol{x}})$, and a priori $\left(\boldsymbol{x}_{\mathrm{a}}\right)$ profiles for temperature over a European background climatology, at $7 \mathrm{~km}$; (b) same as (a), but for a tropical biomass burning climatology at $7 \mathrm{~km}$; (c) same as (a), but for a European background climatology at $2 \mathrm{~km}$; (d) same as (a), but for a tropical biomass burning climatology at $2 \mathrm{~km}$.

is equivalent to a 0.04 change in $\varepsilon_{\mathrm{S}}$ (assuming an initial $T_{\mathrm{S}}$ and $\varepsilon_{\mathrm{s}}$ of $279 \mathrm{~K}$ and 0.97 , respectively). We note that this difference in $\varepsilon_{\mathrm{S}}$ is greater than the expected statistical uncertainty in $\varepsilon_{\mathrm{S}}$ (standard deviation $=0.03$ ) reported by Seemann et al. (2008) for the baseline fit emissivity database used in the retrieval scheme. As we use this database for operational retrievals, the sensitivity test for $T_{\mathrm{s}}$ here implicitly accounts for any likely operational uncertainty in $\varepsilon_{\mathrm{S}}$.

\subsubsection{Water vapour}

Similarly to temperature, well-resolved vertical sensitivity is apparent in water vapour from the sample AKs and DOFS shown in Figs. $4 \mathrm{c}$ and $5 \mathrm{c}$, at 7 and $2 \mathrm{~km}$, respectively. The DOFS range from approximately 1.6 to 3.0 , for the 2 and $7 \mathrm{~km}$ altitudes, respectively (the mean DOFS are given in Tables 3-6 for each scenario). Figures 4-5 (and Tables 3-6) show that the residual spectrum is smaller than the typical instrumental radiometric uncertainty.

The improvement in the retrieval error statistic here is directly comparable to an improvement for the $\mathrm{H}_{2} \mathrm{O}$ partial column relative to the prior information. As seen in Tables 3-6 this error reduction is greater than $50 \%$ for all scenarios and Figs. $4 \mathrm{~d}$ and $5 \mathrm{~d}$ illustrate that this error reduction extends throughout the profile. Tables 3-6 show the total a posteriori errors range from $18.02 \%$ for the BB scenario at $2 \mathrm{~km}$ altitude, to $22.57 \%$ for the EB scenario at $7 \mathrm{~km}$ altitude. The better relative error in the $\mathrm{BB}$ case is due to the presence of
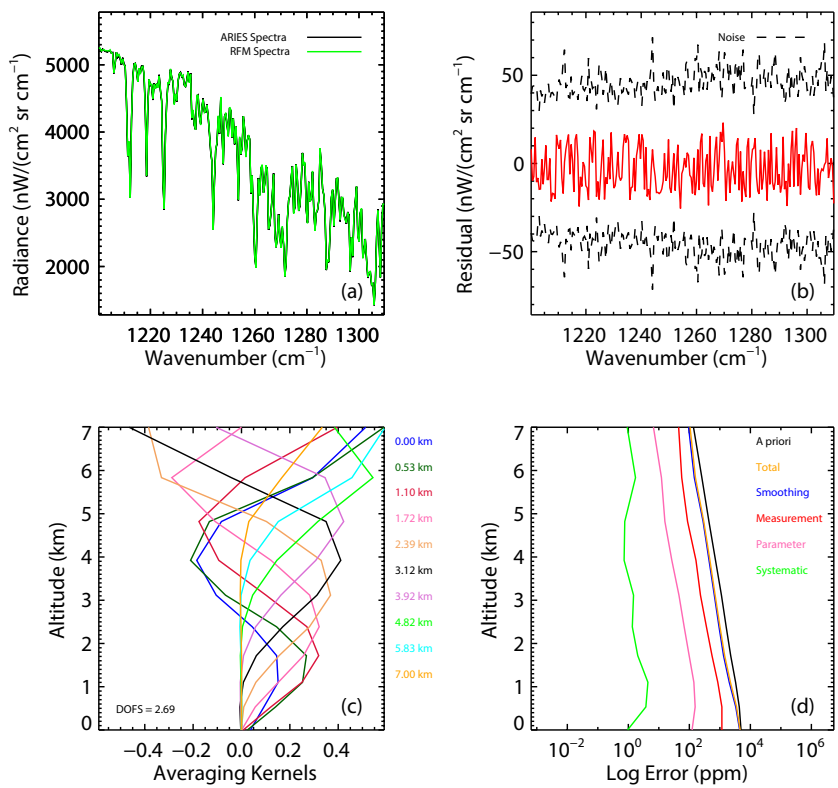

Fig. 4. Typical retrieval metrics for the retrieval of $\mathrm{H}_{2} \mathrm{O}$ from simulated spectra, for an altitude of $7 \mathrm{~km}$ : (a) simulated (ARIES) and retrieved (RFM) spectra, (b) residual difference between ARIES and RFM spectra, (c) averaging kernels for retrieval, and (d) a priori and a posteriori errors.
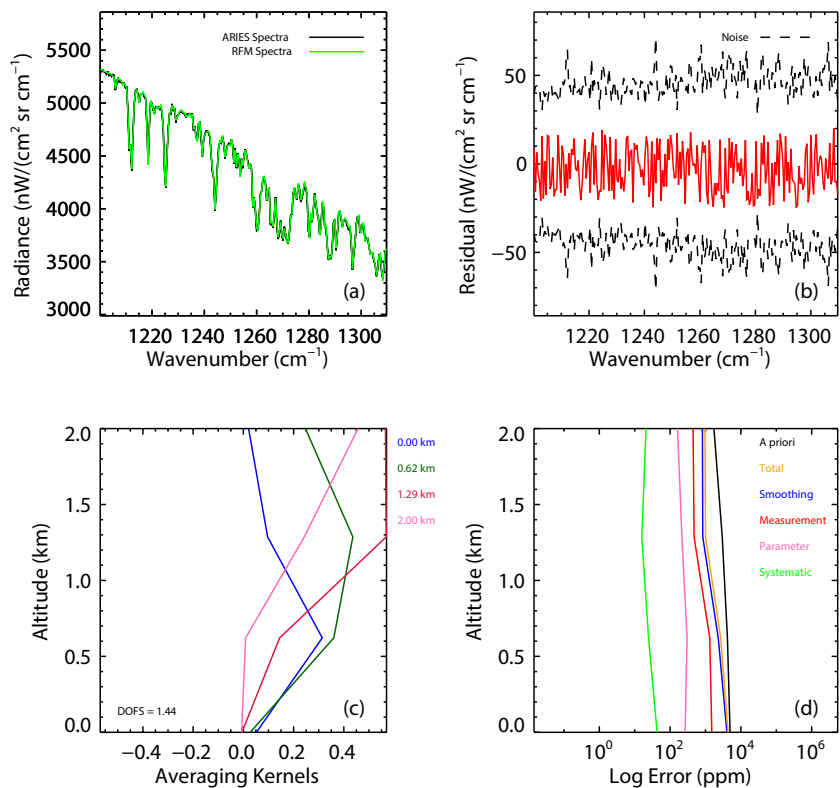

Fig. 5. Typical retrieval metrics for the retrieval of $\mathrm{H}_{2} \mathrm{O}$ from simulated spectra, for an altitude of $2 \mathrm{~km}$ : (a) simulated (ARIES) and retrieved (RFM) spectra, (b) residual difference between ARIES and RFM spectra, (c) averaging kernels for retrieval, and (d) a priori and a posteriori errors. 

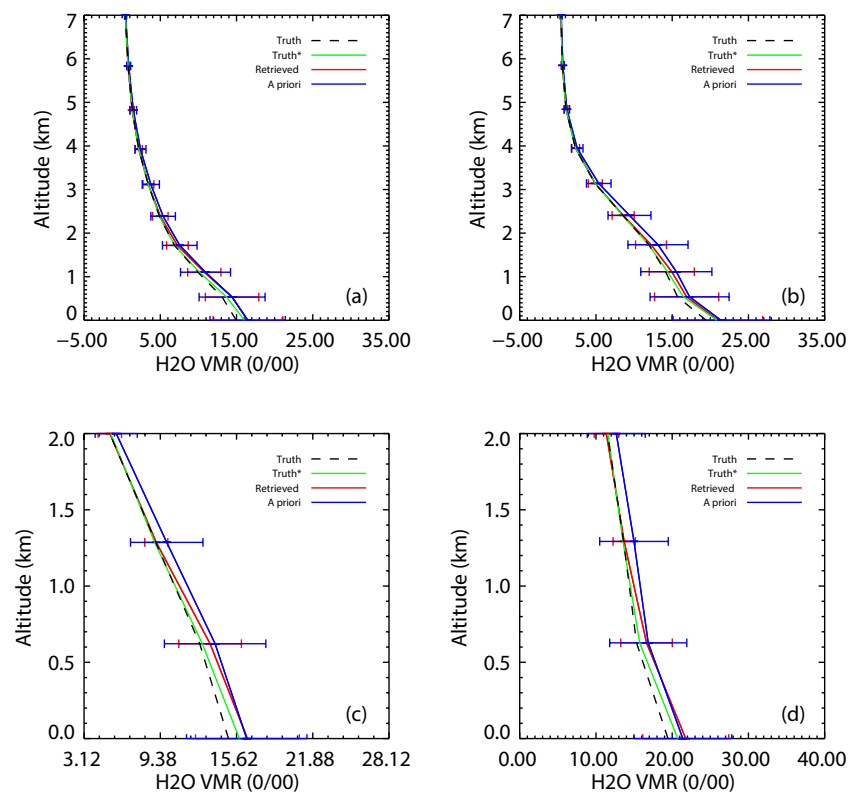

Fig. 6. (a) True $\left(\boldsymbol{x}_{t}\right)$, smoothed truth $\left(\boldsymbol{x}_{t}^{*}\right)$, retrieved $(\hat{\boldsymbol{x}})$, and a priori $\left(\boldsymbol{x}_{\mathrm{a}}\right)$ profiles for $\mathrm{H}_{2} \mathrm{O}$ over a European background climatology, at $7 \mathrm{~km}$; (b) same as (a), but for a tropical biomass burning climatology at $7 \mathrm{~km}$; (c) same as (a), but for a European background climatology at $2 \mathrm{~km}$; (d) same as (a), but for a tropical biomass burning climatology at $2 \mathrm{~km}$.

higher water vapour concentrations in the BB profile compared to the EB case. This error is seen to be minimised in a layer between 1 and $2 \mathrm{~km}$ below the aircraft (Figs. $4 \mathrm{~d}$ and 5d), indicating that when flying at lower altitudes, significant information relating to the near-surface properties can be obtained.

Figure 6 shows a good general agreement between the retrieved and true profiles and the bias between the partial columns of $\boldsymbol{x}_{t}^{*}$ and $\hat{\boldsymbol{x}}$ is low (maximum of $+3.95 \pm 3.11 \%$ at $1 \sigma$ ). The reduction in the bias between $\boldsymbol{x}_{t}$ and $\hat{\boldsymbol{x}}$ (maximum of $+6.76 \pm 3.33 \%$ at $1 \sigma$ ), compared with that between $x_{\mathrm{a}}$ and $\boldsymbol{x}_{t}(10 \%$ as described in Sect. 5.1) also confirms that the ARIES measurements can offer significant information over the ECMWF a priori.

\subsubsection{Carbon monoxide}

The performance of simulated retrievals for $\mathrm{CO}$ can be seen in Figs. 7 and 8. The DOFS for the retrieved profiles (Tables 3-6) range from 0.4 (for the BB scenario at $2 \mathrm{~km}$ ) to 0.9 (for the EB scenario at $7 \mathrm{~km}$ ), indicating that the retrieved $\mathrm{CO}$ product provides at most one piece of independent information relating to the vertical profile. There is also little potential vertical resolution in the retrieved profiles. A comparison between the partial columns is therefore more instructive in the assessment of the retrieval scheme.

From Figs. $7 \mathrm{~b}$ and $8 \mathrm{~b}$ it can be seen that the ARIES retrieval system performs well, with the spectral residual
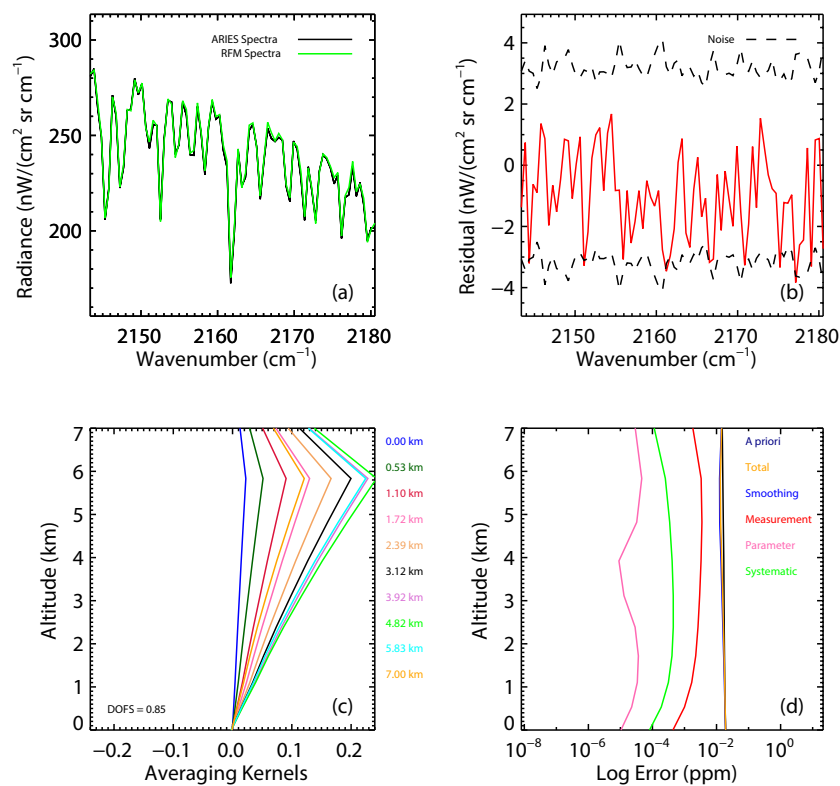

Fig. 7. Typical retrieval metrics for the retrieval of CO from simulated spectra, for an altitude of $7 \mathrm{~km}$ : (a) simulated (ARIES) and retrieved (RFM) spectra, (b) residual difference between ARIES and RFM spectra, (c) averaging kernels for retrieval, and (d) a priori and a posteriori errors.
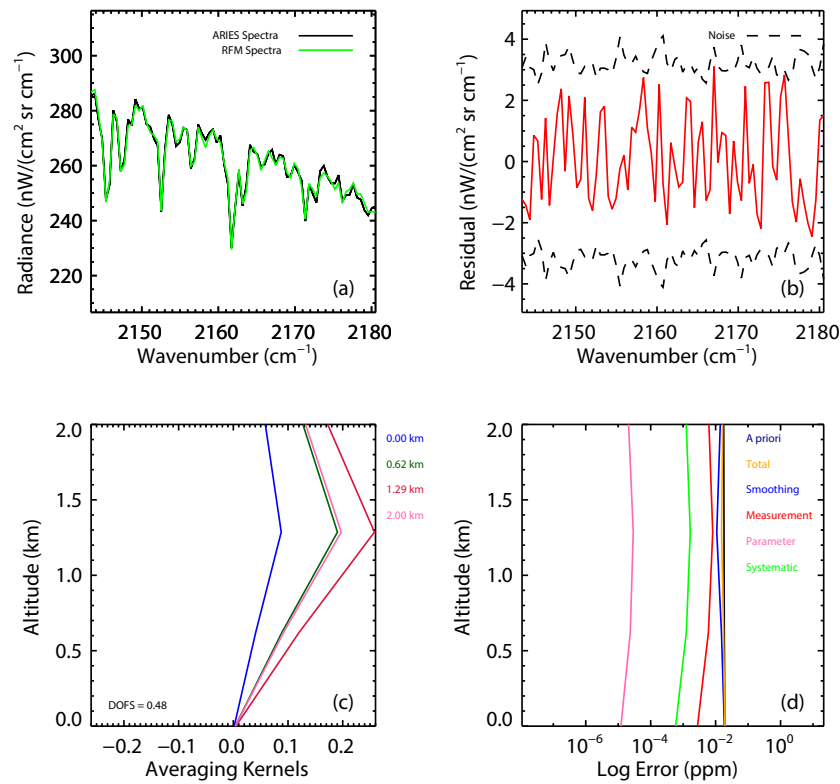

Fig. 8. Typical retrieval metrics for the retrieval of CO from simulated spectra, for an altitude of $2 \mathrm{~km}$ : (a) simulated (ARIES) and retrieved (RFM) spectra, (b) residual difference between ARIES and RFM spectra, (c) averaging kernels for retrieval, and (d) a priori and a posteriori errors. 

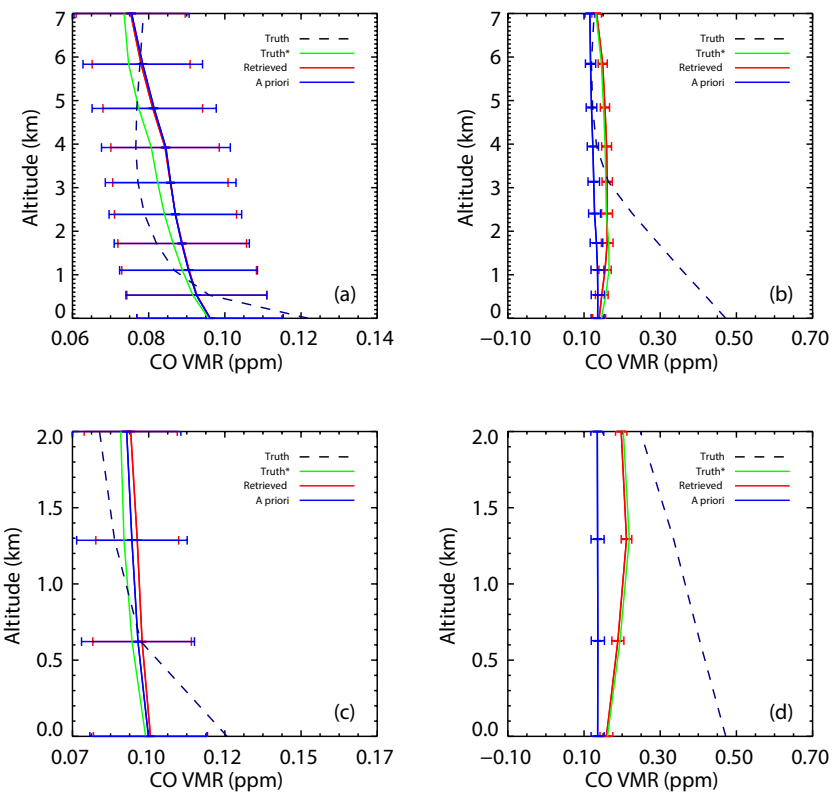

Fig. 9. (a) True $\left(\mathbf{x}_{t}\right)$, smoothed truth $\left(\boldsymbol{x}_{t}^{*}\right)$, retrieved $(\hat{\boldsymbol{x}})$, and a priori $\left(\boldsymbol{x}_{\mathrm{a}}\right)$ profiles for $\mathrm{CO}$ over a European background climatology, at $7 \mathrm{~km}$; (b) same as (a), but for a tropical biomass burning climatology at $7 \mathrm{~km}$; (c) same as (a), but for a European background climatology at $2 \mathrm{~km}$; (d) same as (a), but for a tropical biomass burning climatology at $2 \mathrm{~km}$.

comparable to the typical instrument radiometric uncertainty. Tables 3-6 confirm this across all simulations and also show that the mean number of iterations is typically low, and significantly less than our chosen upper limit of 15 (see Sect. 4.1).

Figures 7 and 8c show AKs and associated DOFS for the sample retrievals illustrated in Figs. 7a and 8a. These show the EB simulations for altitudes of 7 and $2 \mathrm{~km}$, respectively. The AKs show that the peak sensitivity of the retrieval is at about $1 \mathrm{~km}$ below the aircraft with little surface sensitivity. This indicates that for higher altitudes (e.g. $7 \mathrm{~km}$ ), retrievals near the surface are dominated by the a priori. Therefore, in order to obtain information in the near-surface layers, spectra sampled at a lower altitude would be required.

To investigate the effect of surface thermal contrast with the near-surface atmospheric layer, a further set of simulations was performed for the EB at $7 \mathrm{~km}$ (not shown), by simulating a thermal contrast of $5 \mathrm{~K}$. These simulations showed an improvement in the DOFS for the CO retrieval of $\sim 5 \%$, manifesting primarily as an increased sensitivity to the surface as expected. Therefore, it may be expected that for conditions where there is significant thermal contrast, a greater sensitivity towards the near surface would be observed.

Tables 3-6 show that the error reduction for all simulations is greater than $14 \%$, meaning that the retrieved partial column is a significant improvement (in terms of precision) on the a priori. Figures $7 \mathrm{~d}$ and $8 \mathrm{~d}$ show typical total a pos-
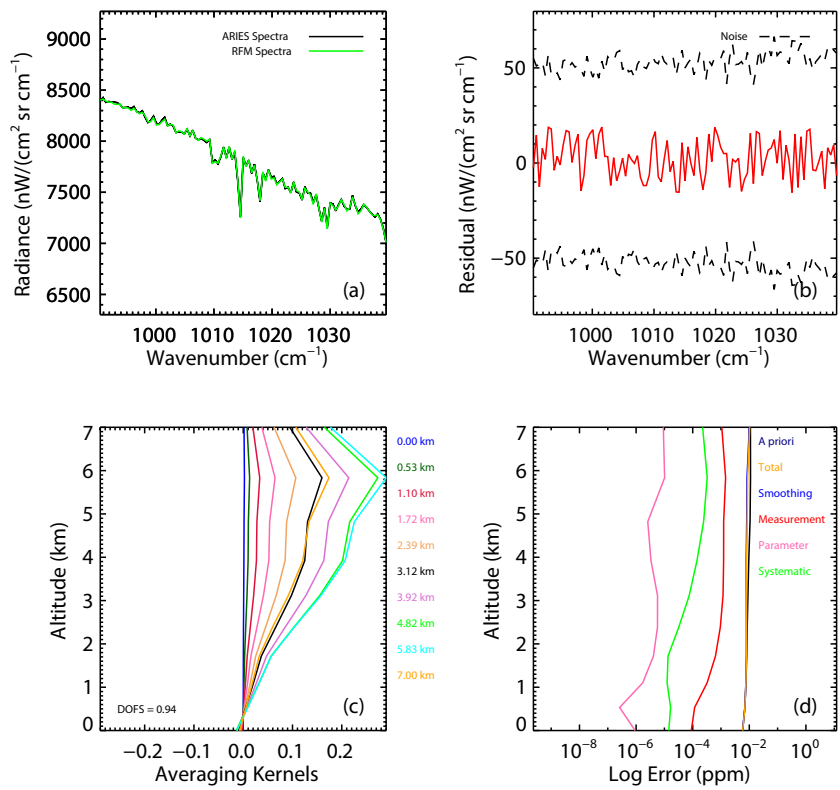

Fig. 10. Typical retrieval metrics for the retrieval of $\mathrm{O}_{3}$ from simulated spectra, for an altitude of $7 \mathrm{~km}$ : (a) simulated (ARIES) and retrieved (RFM) spectra; (b) residual difference between ARIES and RFM spectra; (c) averaging kernels for retrieval; (d) a priori and a posteriori errors.

teriori errors, which range from $7.86 \%$ for the BB scenario at $2 \mathrm{~km}$, to $18.22 \%$ for the EB scenario at $7 \mathrm{~km}$. The better relative performance in the $\mathrm{BB}$ case is due to the higher concentration of $\mathrm{CO}$ in the $\mathrm{BB}$ climatology. These compare to the a posteriori error observed by Illingworth et al. (2011), which was found to be between 18 and $34 \%$ of the partial column for a theoretical study of IASI CO retrievals.

The difference between $\hat{\boldsymbol{x}}$ and $\boldsymbol{x}_{t}^{*}$ (see Fig. 9) shows a maximum bias of $+3.74( \pm 2.97$ at $1 \sigma) \%$. This indicates that MARS is performing well when compared to an optimal scheme. The better agreement between $\hat{\boldsymbol{x}}$ and $\boldsymbol{x}_{t}$ compared to $\boldsymbol{x}_{\mathrm{a}}$ and $\boldsymbol{x}_{t}$ (see Tables 3-6), also shows a large improvement on the a priori (up to $14 \%$ ).

\subsubsection{Ozone}

Figures 10 and 11 and Tables 3-6 indicate that MARS also performs well for the retrieval of $\mathrm{O}_{3}$, with a residual less than the radiometric uncertainty.

The DOFS show that the retrievals of $\mathrm{O}_{3}$ offer at most one piece of independent information in the retrieved profile, with peak sensitivity between approximately 1.0 and $1.5 \mathrm{~km}$ below the altitude of the aircraft (see Figs. 10c and 11c). While for a simulated altitude of $2 \mathrm{~km}$ (Fig. 11c), the DOFS are less than one-third of that calculated for an altitude of $7 \mathrm{~km}$ (Fig. 10c).

The error reduction for each of the simulations is approximately $10-15 \%$. The total a posteriori error is shown in Figs. $10 \mathrm{~d}$ and $11 \mathrm{~d}$ for the EB at 2 and $7 \mathrm{~km}$ altitude, 

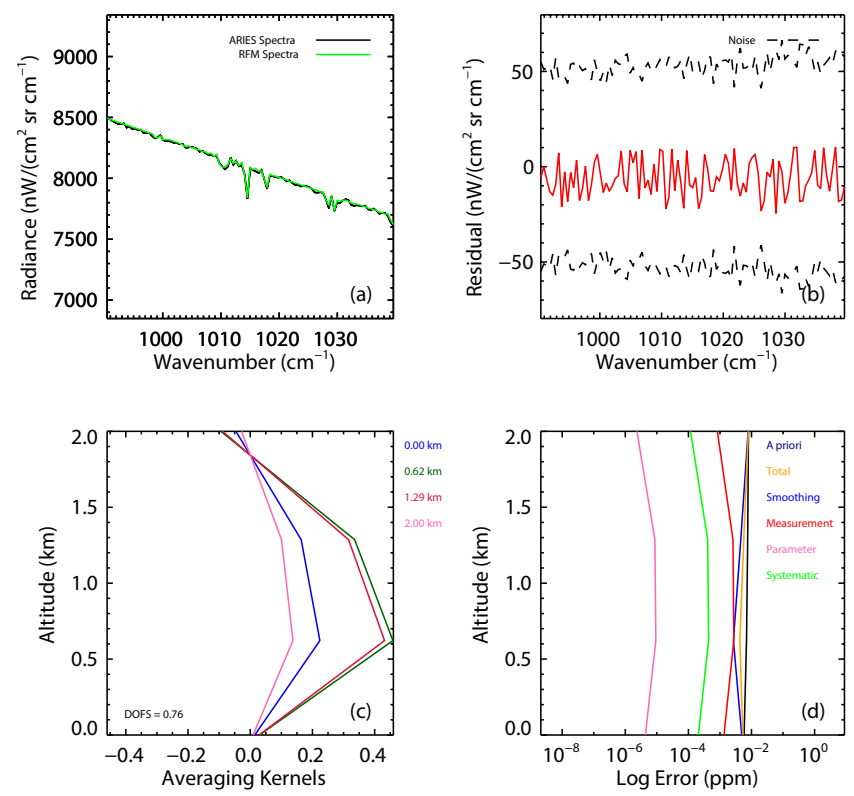

Fig. 11. Typical retrieval metrics for the retrieval of $\mathrm{O}_{3}$ from simulated spectra, for an altitude of $2 \mathrm{~km}$ : (a) simulated (ARIES) and retrieved (RFM) spectra; (b) residual difference between ARIES and RFM spectra; (c) averaging kernels for retrieval; (d) a priori and a posteriori errors.

respectively, which range from $5.85 \%$ for the $\mathrm{BB}$ case at $2 \mathrm{~km}$ to $17.61 \%$ for the EB case at $7 \mathrm{~km}$. These compare favourably to the $28 \%$ error in the partial column between the surface and $6 \mathrm{~km}$ that was reported by Turquety et al. (2004) for IASI tropospheric retrieval.

The relatively small DOFS at $2 \mathrm{~km}$ means that retrieved $\mathrm{O}_{3}$ would be limited to the a priori (as seen in Fig. 13 and Tables 3-6); conversely, there is a more significant divergence toward the truth at $7 \mathrm{~km}$ (Fig. 12a and b). However, the relatively low bias observed between $\hat{\boldsymbol{x}}$ and $\boldsymbol{x}_{t}^{*}$ indicates that the retrieval is performing at near-optimum theoretical potential, with a maximum mean bias of $-8.26( \pm 4.64$ at $1 \sigma) \%$ seen for the EB scenario at $2 \mathrm{~km}$ altitude. In summary, this suggests that useful information for $\mathrm{O}_{3}$ can only be derived for ARIES in the mid-to-upper tropospheric layers regardless of flight altitude.

\subsubsection{Methane}

Figures 13-14 show $\mathrm{CH}_{4}$ retrieval diagnostics for the EB scenario from $7 \mathrm{~km}$ (Fig. 13) and $2 \mathrm{~km}$ (Fig. 14). We see again that the retrieved spectrum is well fitted.

Figures $13 \mathrm{c}$ and $14 \mathrm{c}$ show typical AKs for the $\mathrm{CH}_{4}$ retrievals. The simulations demonstrate maximum vertical sensitivity in a $2 \mathrm{~km}$ layer below the aircraft from all flight altitudes. The mean DOFS range from 0.83 for the EB scenario at $2 \mathrm{~km}$, to 1.45 for the BB scenario at $7 \mathrm{~km}$ (see Tables 3-6).
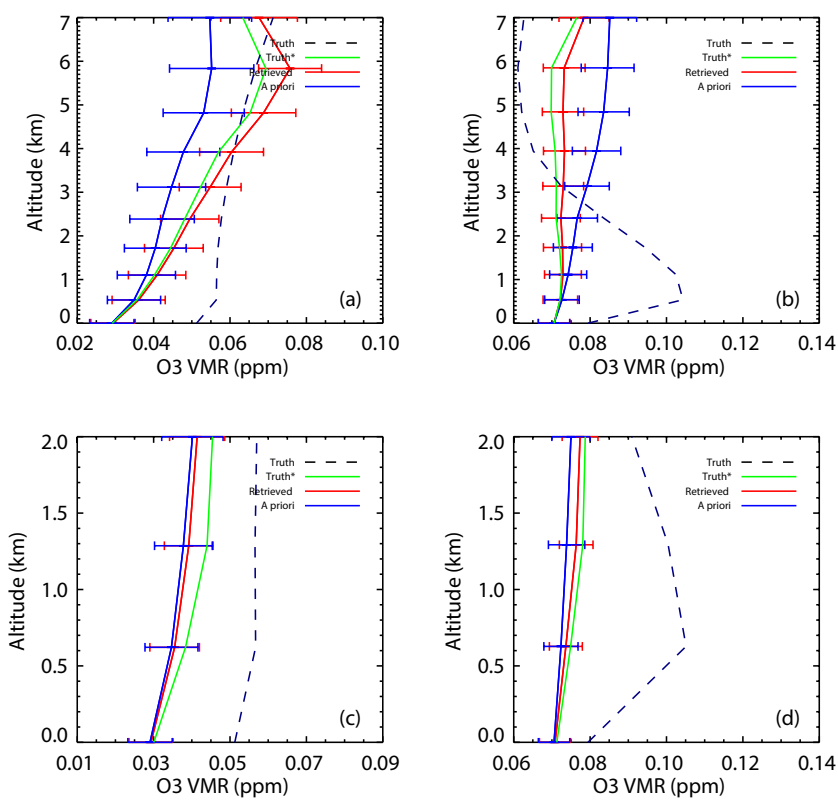

Fig. 12. (a) True $\left(\boldsymbol{x}_{t}\right)$, smoothed truth $\left(\boldsymbol{x}_{t}^{*}\right)$, retrieved $(\hat{\boldsymbol{x}})$, and a priori $\left(\boldsymbol{x}_{\mathrm{a}}\right)$ profiles for $\mathrm{O}_{3}$ over a European background climatology, at $7 \mathrm{~km}$; (b) same as (a), but for a tropical biomass burning climatology at $7 \mathrm{~km}$; (c) same as (a), but for a European background climatology at $2 \mathrm{~km}$; (d) same as (a), but for a tropical biomass burning climatology at $2 \mathrm{~km}$.
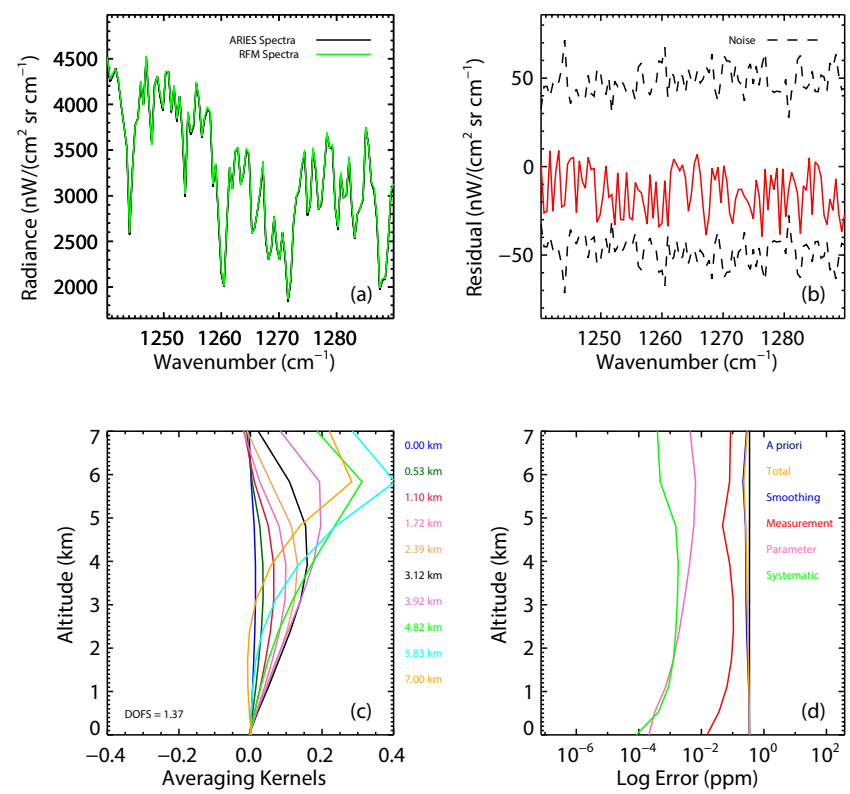

Fig. 13. Typical retrieval metrics for the retrieval of $\mathrm{CH}_{4}$ from simulated spectra, for an altitude of $7 \mathrm{~km}$ : (a) simulated (ARIES) and retrieved (RFM) spectra, (b) residual difference between ARIES and RFM spectra, (c) averaging kernels for retrieval, and (d) a priori and a posteriori errors. 

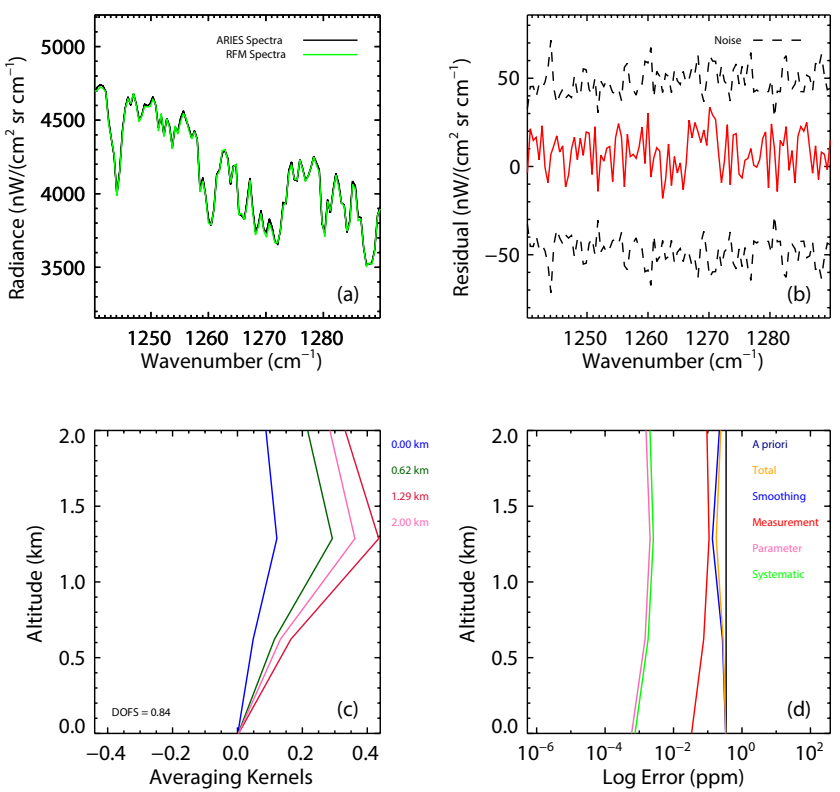

Fig. 14. Typical retrieval metrics for the retrieval of $\mathrm{CH}_{4}$ from simulated spectra, for an altitude of $2 \mathrm{~km}$ : (a) simulated (ARIES) and retrieved (RFM) spectra, (b) residual difference between ARIES and RFM spectra, (c) averaging kernels for retrieval, and (d) a priori and a posteriori errors.

The error reduction ranges from between $\sim 25$ to $40 \%$, indicating that there is a significant improvement in the a posteriori error; although as with all of the retrievals this is determined to some degree by the initial choice of $\mathbf{S}_{\mathrm{a}}$. Figures 13d and $14 \mathrm{~d}$ show typical total a posteriori errors for the retrieval scenarios. These range from $\sim 13 \%$ across the partial column for the BB scenario at $2 \mathrm{~km}$, to $\sim 16 \%$ for the EB scenario at $7 \mathrm{~km}$. The better relative performance in the $\mathrm{BB}$ case is because of higher $\mathrm{CH}_{4}$ concentrations in this climatology.

Figure 15 shows the $\boldsymbol{x}_{\mathrm{a}}, \hat{\boldsymbol{x}}, \boldsymbol{x}_{t}$, and $\boldsymbol{x}_{t}^{*}$ profiles for the simulated scenarios. The retrieved profile does not converge toward truth in the near surface due to the lack of any significant near-surface sensitivity, as shown by the AKs in Figs. $13 \mathrm{c}$ and $14 \mathrm{c}$. Despite the lack of near-surface sensitivity, the performance of the retrieval when compared to the smoothed truth is excellent, with a maximum bias between $\boldsymbol{x}_{t}$ and $\boldsymbol{x}_{t}^{*}$ of $+3.01( \pm 2.61$ at $1 \sigma) \%$, demonstrating that the retrieval is performing near to optimal potential. By comparing $\left(\boldsymbol{x}_{\mathrm{a}}-\boldsymbol{x}_{t}\right)$ to $\left(\hat{\boldsymbol{x}}-\boldsymbol{x}_{t}\right)$ in Tables 3-6 it can be seen that in every scenario there is an improvement relative to the a priori (up to $5 \%$ ).

\section{Conclusions}

This paper has presented the technical design and expected capability of an integrated operational retrieval system for spectral measurements from the ARIES.
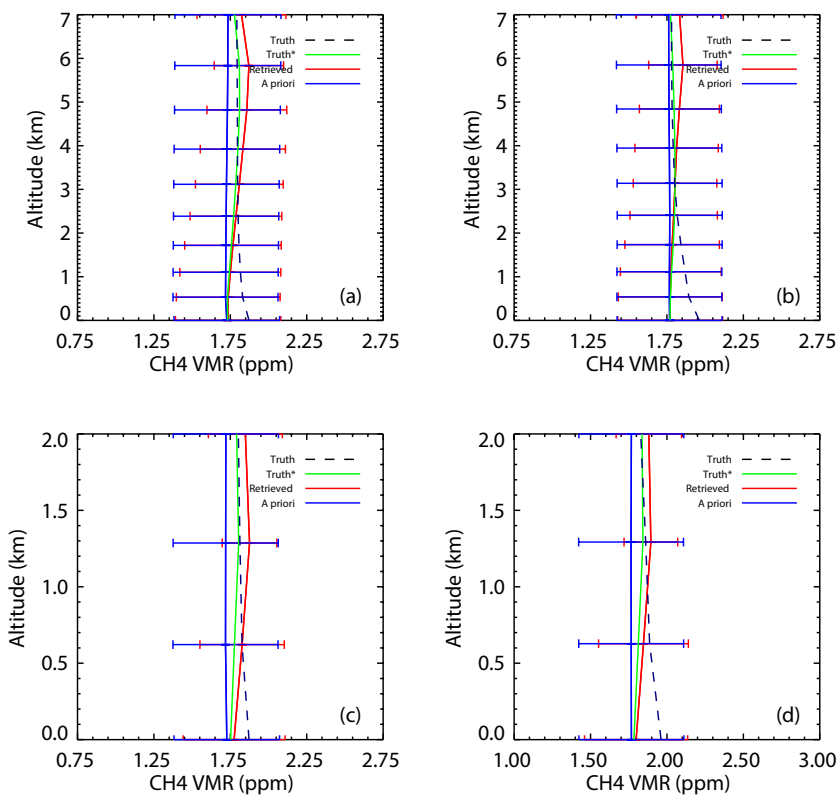

Fig. 15. (a) True $\left(\boldsymbol{x}_{t}\right)$, smoothed truth $\left(\boldsymbol{x}_{t}^{*}\right)$, retrieved $(\hat{\boldsymbol{x}})$, and a priori $\left(\boldsymbol{x}_{\mathrm{a}}\right)$ profiles for $\mathrm{CH}_{4}$ over a European background climatology, at $7 \mathrm{~km}$; (b) same as (a), but for a tropical biomass burning climatology at $7 \mathrm{~km}$; (c) same as (a), but for a European background climatology at $2 \mathrm{~km}$; (d) same as (a), but for a tropical biomass burning climatology at $2 \mathrm{~km}$.

By performing a series of simulations for a variety of GHGs and thermodynamic parameters of known states, the expected capability of the MARS has been assessed across a typical flight altitude range of 2 and $7 \mathrm{~km}$ in two background environments. Retrieved partial columns differ from the smoothed truth in these scenarios by at most +0.06 $( \pm 0.02$ at $1 \sigma) \%,+3.95( \pm 3.11) \%,+3.74( \pm 2.97) \%,-8.26$ $( \pm 4.64) \%$, and $+3.01( \pm 2.61) \%$ for temperature, $\mathrm{H}_{2} \mathrm{O}, \mathrm{CO}$, $\mathrm{O}_{3}$, and $\mathrm{CH}_{4}$ respectively. The expected a posteriori errors for these retrieved products were found to be $0.20,22.57$, $18.22,17.61$, and $16.42 \%$, respectively.

Retrievals of temperature display significant vertical sensitivity (DOFS in the range 2.6 to 4.0 across the altitude range). The water vapour retrievals also resulted in high DOFS of between 1.6 and 3.0, with good sensitivity throughout the partial column. However, a lack of expected vertical resolution (DOFS around unity) for the other trace gases indicates that only partial columns may be usefully reported. Maximum sensitivity for $\mathrm{CO}, \mathrm{O}_{3}$, and $\mathrm{CH}_{4}$ peaks in a layer between 1 to $2 \mathrm{~km}$ below the aircraft. This suggests that flight just above the layer of interest may be necessary to optimise sensitivity for those gases.

In summary, airborne remote sensing in the infrared potentially offers a three-dimensional mapping capability for a range of trace gases and thermodynamic parameters without the need for traversing air masses, allowing simultaneous retrievals of (partially) vertically resolved information below 
and along the aircraft flight path. Such a data set would complement airborne in situ measurement techniques to provide an improved data set for process case studies, monitoring applications and satellite remote-sensing validation.

Further potential retrieval of additional trace gases is expected as future validation data sets become available, with this study providing a framework for the use and interpretation of retrievals from ARIES measured spectra.

Acknowledgements. Airborne data was obtained using the BAe146-301 Atmospheric Research Aircraft flown by Directflight Ltd and managed by FAAM, which is a joint entity of the Natural Environment Research Council and the Met Office. The authors would like to thank the UK Met Office for the operation of the ARIES instrument and for providing data. The authors would also like to thank Peter Bernath for the use of ACE solar spectra, BADC for access to ECMWF data, and the NERC for funding Dr Illingworth (NE/I029293/1) and Dr Allen's Fellowship (NE/I021276/1), as well as NCEO funding for Professor Remedios and Dr Moore. MACC data provided by the MACC-II project were funded by the European Union under the 7th Framework Programme. We thank Lars Fiedler for writing and maintaining the ARIES Calibration Engine (ACE) software used for Level 1 processing of the ARIES spectra.

Edited by: D. Brunner

\section{References}

Albrecht, T., Notholt, J., Wolke, R., Solberg, S., Dye, C., and Malberg, H.: Variations of $\mathrm{CH}_{2} \mathrm{O}$ and $\mathrm{C}_{2} \mathrm{H}_{2}$ determined from ground-based FTIR measurements and comparison with model results, Adv. Space Res., 29, 1713-1718, 2002.

August, T., Klaes, D., Schlüssel, P., Hultberg, T., Crapeau, M., Arriaga, A., O'Carroll, A., Coppens, D., Munro, R., and Calbet, X.: IASI on Metop-A: Operational Level 2 retrievals after five years in orbit, J. Quant. Spectrosc. Ra., 93, 347-370, 2012.

Baran, A. and Francis, P.: On the radiative properties of cirrus cloud at solar and thermal wavelengths: A test of model consistency using high-resolution airborne radiance measurements, Q. J. Roy. Meteorol. Soc., 130, 763-778, 2004.

Birch, J. and Clarke, F.: Fifty categories of ordinate error in Fourier transform spectroscopy, Spectrosc. Europe, 7, 16-22, 1995.

Boynard, A., Clerbaux, C., Coheur, P.-F., Hurtmans, D., Turquety, S., George, M., Hadji-Lazaro, J., Keim, C., and MeyerArnek, J.: Measurements of total and tropospheric ozone from IASI: comparison with correlative satellite, ground-based and ozonesonde observations, Atmos. Chem. Phys., 9, 6255-6271, doi:10.5194/acp-9-6255-2009, 2009.

Chedin, A., Saunders, R., Hollingsworth, A., Scott, N., Matricardi, M., Etcheto, J., Clerbaux, C., Armante, R., and Crevoisier, C.: The feasibility of monitoring $\mathrm{CO}_{2}$ from high-resolution infrared sounders, J. Geophys. Res.-Atmos., 108, 1984-2012, 2003.
Clarisse, L., Coheur, P.-F., Prata, F., Hadji-Lazaro, J., Hurtmans, D., and Clerbaux, C.: A unified approach to aerosol remote sensing and type specification in the infrared, Atmos. Chem. Phys. Discuss., 12, 26871-26928, doi:10.5194/acpd-12-26871-2012, 2012.

Clerbaux, C., Boynard, A., Clarisse, L., George, M., Hadji-Lazaro, J., Herbin, H., Hurtmans, D., Pommier, M., Razavi, A., Turquety, S., Wespes, C., and Coheur, P.-F.: Monitoring of atmospheric composition using the thermal infrared IASI/MetOp sounder, Atmos. Chem. Phys., 9, 6041-6054, doi:10.5194/acp-9-6041-2009, 2009.

Crevoisier, C., Nobileau, D., Fiore, A. M., Armante, R., Chédin, A., and Scott, N. A.: Tropospheric methane in the tropics - first year from IASI hyperspectral infrared observations, Atmos. Chem. Phys., 9, 6337-6350, doi:10.5194/acp-9-6337-2009, 2009.

Deeter, M. N., Edwards, D. P., Gille, J. C., and Drummond, J. R.: Sensitivity of MOPITT observations to carbon monoxide in the lower troposphere, J. Geophys. Res.-Atmos., 112, D24306, doi:10.1029/2007JD008929, 2007b.

Dudhia, A.: Michelson Interferometer for Passive Atmospheric Sounding (MIPAS) Reference Forward Model (RFM), Software User's Manual, 2000.

Edwards, D. P.: GENLN2: A general line-by-line atmospheric transmittance and radiance model, NCAR Tech.Note, NCAR/TN367+STR, 1992.

Engel-Cox, J. A., Hoff, R. M., and Haymet, A.: Recommendations on the use of satellite remote-sensing data for urban air quality, J. Air Waste Manage. Assoc., 54, 1360-1371, 2004.

Eremenko, M., Dufour, G., Foret, G., Keim, C., Orphal, J., Beekmann, M., Bergametti, G., and Flaud, J. M.: Tropospheric ozone distributions over Europe during the heat wave in July 2007 observed from infrared nadir spectra recorded by IASI, Geophys Res. Lett., 35, L18805, doi:10.1029/2008GL034803, 2008.

Fillion, L. and Mahfouf, J.-F. C.: Coupling of moist-convective and stratiform precipitation processes for variational data assimilation, Mon. Weather Rev., 128, 109-124, 2000.

Fischer, H., Birk, M., Blom, C., Carli, B., Carlotti, M., von Clarmann, T., Delbouille, L., Dudhia, A., Ehhalt, D., Endemann, M., Flaud, J. M., Gessner, R., Kleinert, A., Koopman, R., Langen, J., López-Puertas, M., Mosner, P., Nett, H., Oelhaf, H., Perron, G., Remedios, J., Ridolfi, M., Stiller, G., and Zander, R.: MIPAS: an instrument for atmospheric and climate research, Atmos. Chem. Phys., 8, 2151-2188, doi:10.5194/acp-8-2151-2008, 2008.

George, M., Clerbaux, C., Hurtmans, D., Turquety, S., Coheur, P.F., Pommier, M., Hadji-Lazaro, J., Edwards, D. P., Worden, H., Luo, M., Rinsland, C., and McMillan, W.: Carbon monoxide distributions from the IASI/METOP mission: evaluation with other space-borne remote sensors, Atmos. Chem. Phys., 9, 8317-8330, doi:10.5194/acp-9-8317-2009, 2009.

Gerilowski, K., Tretner, A., Krings, T., Buchwitz, M., Bertagnolio, P. P., Belemezov, F., Erzinger, J., Burrows, J. P., and Bovensmann, H.: MAMAP - a new spectrometer system for columnaveraged methane and carbon dioxide observations from aircraft: instrument description and performance analysis, Atmos. Meas. Tech., 4, 215-243, doi:10.5194/amt-4-215-2011, 2011.

Grieco, G., Masiello, G., Matricardi, M., and Serio, C.: Partially scanned interferogram methodology applied to IASI for the retrieval of $\mathrm{CO}, \mathrm{CO}_{2}, \mathrm{CH}_{4}$ and $\mathrm{N}_{2} \mathrm{O}$, Opt. Express, 21, 2475324769, 2013. 
Hase, F., Wallace, L., McLeod, S. D., Harrison, J. J., and Bernath, P. F.: The ACE-FTS atlas of the infared solar spectrum, J. Quant. Spectrosc. Ra., 111, 521-528, 2010.

Highwood, E. J., Haywood, J. M., Silverstone, M. D., Newman, S. M., and Taylor, J. P.: Radiative properties and direct effect of Saharan dust measured by the C-130 aircraft during Saharan Dust Experiment (SHADE): 2. Terrestrial spectrum, J. Geophys. Res.-Atmos., 108, 1984-2012, 2003.

Höpfner, M., von Clarmann, T., Fischer, H., Funke, B., Glatthor, N., Grabowski, U., Kellmann, S., Kiefer, M., Linden, A., Milz, M., Steck, T., Stiller, G. P., Bernath, P., Blom, C. E., Blumenstock, Th., Boone, C., Chance, K., Coffey, M. T., Friedl-Vallon, F., Griffith, D., Hannigan, J. W., Hase, F., Jones, N., Jucks, K. W., Keim, C., Kleinert, A., Kouker, W., Liu, G. Y., Mahieu, E., Mellqvist, J., Mikuteit, S., Notholt, J., Oelhaf, H., Piesch, C., Reddmann, T., Ruhnke, R., Schneider, M., Strandberg, A., Toon, G., Walker, K. A., Warneke, T., Wetzel, G., Wood, S., and Zander, R.: Validation of MIPAS ClONO2 measurements, Atmos. Chem. Phys., 7, 257-281, doi:10.5194/acp-7-257-2007, 2007.

Houghton, J. T., Taylor, F., and Rodgers, C. D.: Remote sounding of atmospheres, Cambridge University Press, 1986.

Illingworth, S. M., Remedios, J. J., Boesch, H., Moore, D. P., Sembhi, H., Dudhia, A., and Walker, J. C.: ULIRS, an optimal estimation retrieval scheme for carbon monoxide using IASI spectral radiances: sensitivity analysis, error budget and simulations, Atmos. Meas. Tech., 4, 269-288, doi:10.5194/amt-4-269-2011, 2011.

Inness, A., Baier, F., Benedetti, A., Bouarar, I., Chabrillat, S., Clark, H., Clerbaux, C., Coheur, P., Engelen, R. J., Errera, Q., Flemming, J., George, M., Granier, C., Hadji-Lazaro, J., Huijnen, V., Hurtmans, D., Jones, L., Kaiser, J. W., Kapsomenakis, J., Lefever, K., Leitão, J., Razinger, M., Richter, A., Schultz, M. G., Simmons, A. J., Suttie, M., Stein, O., Thépaut, J.-N., Thouret, V., Vrekoussis, M., Zerefos, C., and the MACC team: The MACC reanalysis: an $8 \mathrm{yr}$ data set of atmospheric composition, Atmos. Chem. Phys., 13, 4073-4109, doi:10.5194/acp-13-4073-2013, 2013

Kulawik, S. S., Worden, J., Eldering, A., Bowman, K., Gunson, M., Osterman, G. B., Zhang, L., Clough, S. A., Shephard, M. W., and Beer, R.: Implementation of cloud retrievals for Tropospheric Emission Spectrometer (TES) atmospheric retrievals: part 1. Description and characterization of errors on trace gas retrievals, J. Geophys. Res.-Atmos., 111, 1984-2012, 2006.

Larar, A. M., Smith, W. L., Zhou, D. K., Liu, X., Revercomb, H., Taylor, J. P., Newman, S. M., and Schlüssel, P.: IASI spectral radiance validation inter-comparisons: case study assessment from the JAIVEx field campaign, Atmos. Chem. Phys., 10, 411-430, doi:10.5194/acp-10-411-2010, 2010.

Larar, A. M., Smith, W. L., Zhou, D. K., Liu, X., Noe, A., Flood, D. O. M., Rochette, L., and Tian, J.: An update on the NAST-I airborne FTS, 2011.

Levelt, P. F., Veefkind, J. P., Kerridge, B. J., Siddans, R., de Leeuw, G., Remedios, J. J., and Coheur, P. F.: CAMELOT Final Report, Issue 1, ESA, 2009.

Masiello, G. and Serio, C.: Simultaneous physical retrieval of surface emissivity spectrum and atmospheric parameters from infrared atmospheric sounder interferometer spectral radiances, Appl. Opt., 52, 2428-2446, 2013.
McMillan, W. W., Barnet, C., Strow, L., Chahine, M. T., McCourt, M. L., Warner, J. X., Novelli, P. C., Korontzi, S., Maddy, E. S., and Datta, S.: Daily global maps of carbon monoxide from NASA's Atmospheric Infrared Sounder, Geophys. Res. Lett., 32 $1-4,2005$.

Moore, D. P. and Remedios, J. J.: Seasonality of Peroxyacetyl nitrate (PAN) in the upper troposphere and lower stratosphere using the MIPAS-E instrument, Atmos. Chem. Phys., 10, 6117-6128, doi:10.5194/acp-10-6117-2010, 2010.

Newman, S. M. and Taylor, J. P.: Impact of updates to the HITRAN spectroscopic database on the modeling of clear-sky infrared radiances, Geophys. Res. Lett., 29, 1957, doi:10.1029/2002GL015832, 2002.

Newman, S., Smith, J., Glew, M., Rogers, S., and Taylor, J.: Temperature and salinity dependence of sea surface emissivity in the thermal infrared, Q. J. Roy. Meteorol. Soc., 131, 2539-2557, 2005 .

Newman, S. M., Larar, A. M., Smith, W. L., Ptashnik, I. V., Jones, R. L., Mead, M. I., Revercomb, H., Tobin, D. C., Taylor, J. K., and Taylor, J. P.: The Joint Airborne IASI Validation Experiment: An evaluation of instrument and algorithms, J. Quant. Spectrosc. Ra., 113, 1372-1390, doi:10.1016/j.jqsrt.2012.02.030, 2012.

Quan, X., Huang, H.-L., Zhang, L., Weisz, E., and Cao, X.: Sensitive Detection of Aerosol Effect on Simulated IASI Spectral Radiance, J. Quant. Spectrosc. Ra., 122, 214-232, 2012.

Razavi, A., Clerbaux, C., Wespes, C., Clarisse, L., Hurtmans, D., Payan, S., Camy-Peyret, C., and Coheur, P. F.: Characterization of methane retrievals from the IASI space-borne sounder, Atmos. Chem. Phys., 9, 7889-7899, doi:10.5194/acp-9-7889-2009, 2009.

Remedios, J. J., Allen, G., Waterfall, A. M., Oelhaf, H., Kleinert, A., and Moore, D. P.: Detection of organic compound signatures in infra-red, limb emission spectra observed by the MIPASB2 balloon instrument, Atmos. Chem. Phys., 7, 1599-1613, doi:10.5194/acp-7-1599-2007, 2007 .

Remedios, J. J., Leigh, R. J., Waterfall, A. M., Moore, D. P., Sembhi, H., Parkes, I., Greenhough, J., Chipperfield, M.P., and Hauglustaine, D.: MIPAS reference atmospheres and comparisons to V4.61/V4.62 MIPAS level 2 geophysical data sets, Atmos. Chem. Phys. Discuss., 7, 9973-10017, doi:10.5194/acpd-79973-2007, 2007b.

Rinsland, C. P., Goldman, A., Mahieu, E., Zander, R., Notholt, J., Jones, N. B., Griffith, D., Stephen, T., and Chiou, L.: Groundbased infrared spectroscopic measurements of carbonyl sulfide: Free tropospheric trends from a 24-year time series of solar absorption measurements, J. Geophys. Res., 107, 4657, 2002.

Rizzi, R., di Pietro, P., Loffredo, G., and Smith, J. A.: Comparison of measured and modeled stratus cloud infrared spectral signatures, J. Geophys. Res.-Atmos. (1984-2012), 106, 34109-34119, 2001.

Rodgers, C. D.: Inverse Methods for Atmospheric Sounding: Theory and Practice, World Scientific, 2000.

Rodgers, C. D. and Connor, B. J.: Intercomparison of remote sounding instruments, J. Geophys. Res.-Atmos., 108, ACH 13-11ACH 13-14, 2003.

Ross, A. N., Wooster, M. J., Boesch, H., and Parker, R.: First satellite measurements of carbon dioxide and methane emission ratios in wildfire plumes, Geophys. Res. Lett., 40, 4098-4102, 2013. 
Rothman, L., Gordon, I., Babikov, Y., Barbe, A., Benner, D. C., Bernath, P., Birk, M., Bizzocchi, L., Boudon, V., and Brown, L.: The HITRAN2012 Molecular Spectroscopic Database, J. Quant. Spectrosc. Ra., 130, 4-50, 2013.

Schneider, M. and Hase, F.: Optimal estimation of tropospheric $\mathrm{H}_{2} \mathrm{O}$ and $\delta \mathrm{D}$ with IASI/METOP, Atmos. Chem. Phys., 11, 11207-11220, doi:10.5194/acp-11-11207-2011, 2011.

Seemann, S. W., Borbas, E. E., Knuteson, R. O., Stephenson, G. R., and Huang, H.-L.: Development of a global infrared land surface emissivity database for application to clear sky sounding retrievals from multispectral satellite radiance measurements, J. Appl. Meteorol. Climatol., 47, 108-123, 2008.

Strabala, K. I., Ackerman, S. A., and Menzel, W. P.: Cloud properties inferred from 8-12 $\mu \mathrm{m}$ data, J. Appl. Meteorol., 33, 212-229, 1994.

Taylor, J. P., Newman, S. M., Hewison, T. J., and McGRATH, A.: Water vapour line and continuum absorption in the thermal infrared-reconciling models and observations, Q. J. Roy. Meteorol. Soc., 129, 2949-2969, 2003.

Thelen, J.-C., Havemann, S., Newman, S. M., and Taylor, J. P.: Hyperspectral retrieval of land surface emissivities using ARIES, Q. J. Roy. Meteorol. Soc., 135, 2110-2124, 2009.

Thorpe, A. K., Frankenberg, C., and Roberts, D. A.: Retrieval techniques for airborne imaging of methane concentrations using high spatial and moderate spectral resolution: application to AVIRIS, Atmos. Meas. Tech., 7, 491-506, doi:10.5194/amt-7491-2014, 2014.

Tjemkes, S. A., Patterson, T., Rizzi, R., Shephard, M. W., Clough, S. A., Matricardi, M., Haigh, J. D., Höpfner, M., Payan, S., Trotsenko, A., Scott, N., Rayer, P., Taylor, J. P., Clerbaux, C., Strow, L. L., DeSouza-Machado, S., Tobin, D., and Knuteson, R.: The ISSWG line-by-line inter-comparison experiment, J. Quant. Spectrosc. Ra., 77, 433-453, 2003.

Tobin, D. C., Revercomb, H. E., Knuteson, R. O., Best, F. A., Smith, W. L., Ciganovich, N. N., Dedecker, R. G., Dutcher, S., Ellington, S. D., Garcia, R. K., Howell, H. B., LaPorte, D. D., Mango, S. A., Pagano, T. S., Taylor, J. K., van Delst, P., Vinson, K. H., and Werner, M. W.: Radiometric and spectral validation of Atmospheric Infrared Sounder observations with the aircraft-based Scanning High-Resolution Interferometer Sounder, J. Geophys. Res.-Atmos., 111, D09S02, doi:10.1029/2005JD006094, 2006.
Turquety, S., Hadji-Lazaro, J., Clerbaux, C., Hauglustaine, D., Clough, S., Cassé, V., Schlüssel, P., and Mégie, G.: Operational trace gas retrieval algorithm for the Infrared Atmospheric Sounding Interferometer, J. Geophys. Res.-Atmos., 109, 1984-2012, 2004.

USGS: US Geological Survey: GTOPO30 Global 30 Arc-second Digital Elevation Model, US Geological Survey, EROS Data Center Distributed Active Archive Center (EDC DAAC), 1998.

Verstraeten, W. W., Boersma, K. F., Zörner, J., Allaart, M. A. F., Bowman, K. W., and Worden, J. R.: Validation of six years of TES tropospheric ozone retrievals with ozonesonde measurements: implications for spatial patterns and temporal stability in the bias, Atmos. Meas. Tech., 6, 1413-1423, doi:10.5194/amt-61413-2013, 2013.

Wilson, S., Atkinson, N., and Smith, J.: The development of an airborne infrared interferometer for meteorological sounding studies, J. Atmos. Ocean. Technol., 16, 1912-1927, 1999.

Woiwode, W., Oelhaf, H., Gulde, T., Piesch, C., Maucher, G., Ebersoldt, A., Keim, C., Höpfner, M., Khaykin, S., Ravegnani, F., Ulanovsky, A. E., Volk, C. M., Hösen, E., Dörnbrack, A., Ungermann, J., Kalicinsky, C., and Orphal, J.: MIPAS-STR measurements in the Arctic UTLS in winter/spring 2010: instrument characterization, retrieval and validation, Atmos. Meas. Tech., 5, 1205-1228, doi:10.5194/amt-5-1205-2012, 2012.

Worden, J., Wecht, K., Frankenberg, C., Alvarado, M., Bowman, K., Kort, E., Kulawik, S., Lee, M., Payne, V., and Worden, H.: $\mathrm{CH}_{4}$ and $\mathrm{CO}$ distributions over tropical fires during October 2006 as observed by the Aura TES satellite instrument and modeled by GEOS-Chem, Atmos. Chem. Phys., 13, 3679-3692, doi:10.5194/acp-13-3679-2013, 2013.

Yokota, T., Yoshida, Y., Eguchi, N., Ota, Y., Tanaka, T., Watanabe, H., and Maksyutov, S.: Global concentrations of $\mathrm{CO}_{2}$ and $\mathrm{CH}_{4}$ retrieved from GOSAT: First preliminary results, Sola, 5, 160163, 2009. 